\title{
ZEOLITES AND ZEOLITE-BASED MATERIALS IN EXTRACTION AND MICROEXTRACTION TECHNIQUES
}

Paola Baile, Elena Fernández, Lorena Vidal* and Antonio Canals

Departamento de Química Analítica, Nutrición y Bromatología e Instituto

Universitario de Materiales, Universidad de Alicante, P.O. Box 99, E-03080

Alicante, Spain.

*Corresponding author: Tel.: +34965903400; fax: +34965903697.

E-mail address: lorena.vidal@ua.es (L. Vidal)

\begin{abstract}
Zeolites are ordered crystalline materials with a promising performance for a wide range of applications such as catalysis, petrochemistry, environmental remediation and medicine, but scarcely evaluated in Analytical Chemistry. Their unique and fascinating properties such as high surface area, high adsorption capacity and molecular selectivity, chemical and thermal stability, ion-exchange capacity, low cost extraction and synthesis, and their easy modification, which provides a wide range of zeolite-based materials, convert zeolites in potential sorbents for extraction procedures. Therefore, in this review we provide an overview at the current status of zeolites and zeolite-based materials used in extraction and microextraction techniques with reference to recent applications and highlighting some of the novel advances.
\end{abstract}

Keywords: zeolite; zeolite-based materials; extraction; microextraction;; metals; organic compounds. 


\section{LIST OF ABBREVIATIONS}

\begin{tabular}{|c|c|}
\hline 2,6-DAP & 2,6-diacetyl pyridine \\
\hline 5-Br-PADAP & 2-(5-bromo-2-pyridylazo)-5-diethylaminophenol \\
\hline AChE & Acetylcholinesterase \\
\hline APDC & Ammonium pyrrolidine dithiocarbamate \\
\hline ASDPV & Anodic stripping differential pulse voltammetry \\
\hline BDTA & Benzyldimethyltetradecylammonium \\
\hline BDTA-Cl & Benzyldimethyltetradecylammonium chloride \\
\hline BTEX & Benzene, toluene, ethylbenzene and xylenes \\
\hline BTX & Benzene, toluene and xylenes \\
\hline $\mathrm{CC}[4] \mathrm{A}$ & Carboxylatocalix[4]arenes \\
\hline CEC & Cation-exchange capacity \\
\hline CMC & Critical micelle concentration \\
\hline CTA & Cetyltrimethylammonium \\
\hline CTA-Br & Cetyltrimethylammonium bromide \\
\hline$D-\mu-S P E$ & Dispersive micro-solid-phase extraction \\
\hline DDTC & Sodium diethyldithiocarbamate trihydrate \\
\hline DHPDT & 2-(3,4-dihydroxyphenyl)-1,3-dithiane \\
\hline DI & Direct immersion \\
\hline DMF & Dimethylformamide \\
\hline DMSO & Dimethylsulfoxide \\
\hline DR-UV & Diffuse reflectance ultraviolet \\
\hline DSPE & Dispersive solid-phase extraction \\
\hline EDTA & Ethylenediaminetetraacetic acid \\
\hline EDX & Energy dispersive $\mathrm{X}$-ray \\
\hline ETAAS & Electrothermal atomic absorption spectrometry \\
\hline FAAS & Flame atomic absorption spectrometry \\
\hline FDS & First-order derivative spectrophotometry \\
\hline FDS-HPSAM & First-order derivative spectrophotometry- $\mathrm{H}$-point standard addition method \\
\hline FE-SEM & Field emission scanning electron microscopy \\
\hline FI-FAAS & Flow injection flame atomic absorption spectrometry \\
\hline FT-IR & Fourier Transform Infrared \\
\hline
\end{tabular}




\begin{tabular}{|c|c|}
\hline G-CL & Graphene-clinoptilolite \\
\hline GC-FID & Gas chromatography-flame ionization detection \\
\hline GC-MS & Gas chromatography-mass spectrometry \\
\hline GFAAS & Graphite furnace atomic absorption spectrometry \\
\hline HDTMA & Hexadecyltrimethylammonium \\
\hline HDTMA-Br & Hexadecyltrimethylammonium bromide \\
\hline HPLC-PDA & High-performance liquid chromatography-photodiode array detection \\
\hline HPSAM & H-point standard addition method \\
\hline HS & Headspace \\
\hline ICP AES & Inductively coupled plasma atomic emission spectrometry \\
\hline ICP OES & Inductively coupled plasma optical emission spectrometry \\
\hline IZA & International Zeolite Association \\
\hline LC-FD & Liquid chromatography-fluorescence detection \\
\hline LC-MWD & Liquid chromatography-multiple wavelength detection \\
\hline LC-PDA & Liquid chromatography-photodiode array detection \\
\hline LC-UV & Liquid chromatography-ultraviolet detection \\
\hline LC-UVIFD & Liquid chromatography-ultraviolet/fluorescence detection \\
\hline LETRSS & Laser-excited time-resolved Shpol'skii spectroscopy \\
\hline LODs & Limits of detection \\
\hline LTA & Linde Type A \\
\hline LTL & Linde Type L \\
\hline MIBK & Methyl isobutyl ketone \\
\hline MS & Mass spectrometry \\
\hline MSPE & Magnetic solid-phase extraction \\
\hline Neothorin & 3-(2-arsenophenylazo)-4,5-dihydroxy-2,7-naphthalene disulfonic acic \\
\hline Nitroso-S & 2-nitroso-1-naphthol-4-sulfonic acid \\
\hline ODTMA & Octadecyltrimethylammonium \\
\hline ODTMA-Br & Octadecyltrimethylammonium bromide \\
\hline PA & 3-aminopropyl trimethoxy silane \\
\hline PAHs & Polycyclic aromatic hydrocarbons \\
\hline PAN & 1-(2-pyridylazo)-2-naphtol \\
\hline PANI & Polyaniline \\
\hline PAR & 4-(2-pyridylazo)resorcinol \\
\hline
\end{tabular}


TDMBA Tetradecyldimethylbenzylammonium

TDMBA-CI Tetradecyldimethylbenzylammonium chloride

TDS

Third-order derivative spectrophotometry

TFME

Thin-film microextraction

TMA Tetramethylammonium

TMA-Br Tetramethylammonium bromide

TMA-Cl Tetramethylammonium chloride

TPPZ 2,3,5,6-tetra(2-pyridyl)pyrazine

UPLC-Q-TOF-MS Ultra-high performance liquid chromatography-quadrupole time-of-flight mass spectrometry

UV-vis Ultraviolet-visible

Vocs Volatile organic compounds

XRD

X-ray diffraction

Zincon

2-[1-(2-hydroxy-5-sulforphenyl)-3-phenyl-5-formazano]-benzoic acid monosodium salt

ZSM-5 Zeolite Socony Mobil-5

$\mu$-SPE

Micro-solid-phase extraction 


\section{Contents}

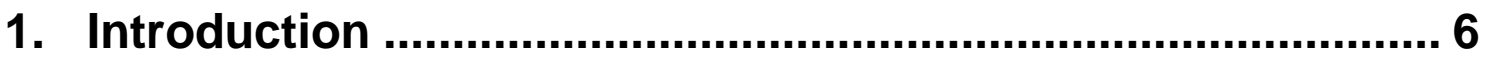

2. Zeolites and zeolite-based materials in extraction and microextraction techniques .................................................... 12

3. Extraction of organic compounds.................................... 17

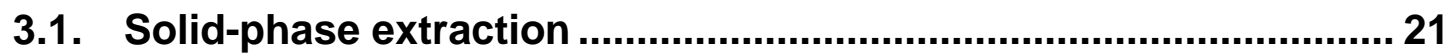

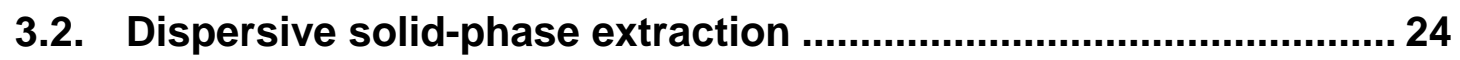

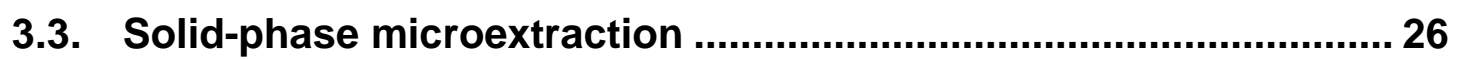

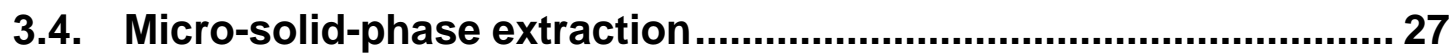

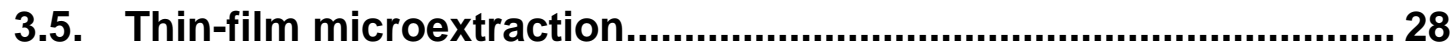

3.6. Polymer monolith microextraction ............................................... 29

3.7. Dispersive micro-solid-phase extraction........................................ 30

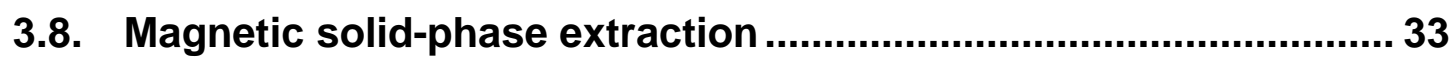

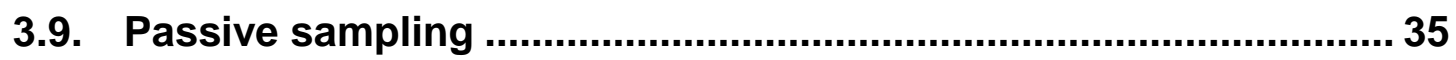

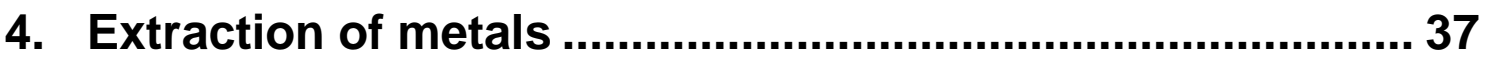

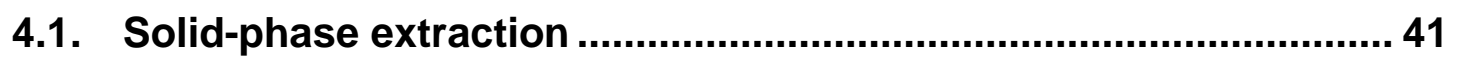

4.2. Dispersive micro-solid-phase extraction........................................53

4.3. Magnetic solid-phase extraction .................................................... 55

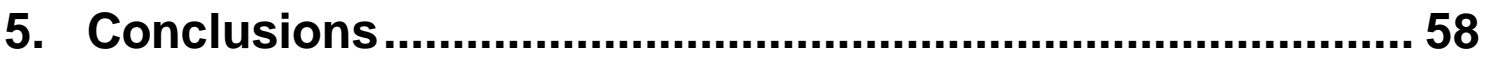

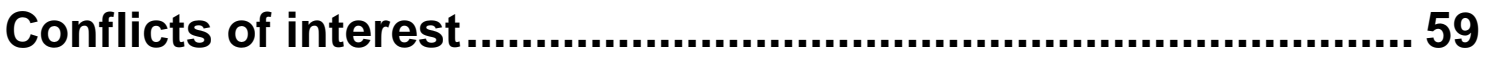

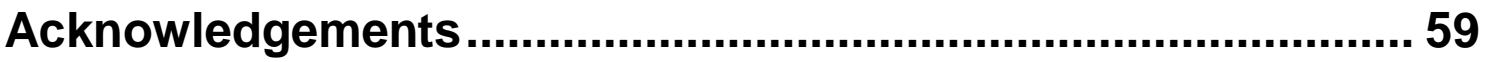

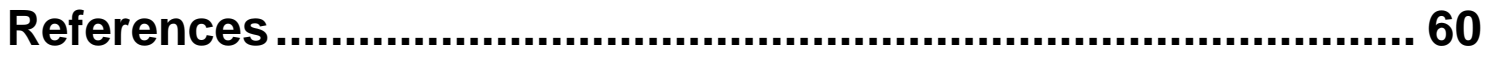




\section{Introduction}

Mineralogist Cronstedt used the term zeolite for the first time in the middle of the $18^{\text {th }}$ century (1756) to describe an aluminosilicate mineral (some authors identified this mineral as stilbite). ${ }^{1,2}$ Etymologically, this term is derived from two Greek words, the word "zeo" means boiling and the word "lithos" means stone, since this mineral releases and adsorbs water once is heated and cooled, respectively. ${ }^{1,3}$ Zeolites are naturally originated at mines and more than 60 natural zeolites are known nowadays in the world, although new zeolite minerals are constantly identified. ${ }^{1}$ Among these natural zeolites, clinoptilolite, mordenite, phillipsite, chabazite, stilbite, analcime, laumontite and erionite are the most commonly evaluated. ${ }^{4}$ Furthermore, zeolites can also be synthetically prepared in the laboratory and in fact the number of synthetic zeolites is constantly increasing every year. Though the existence of natural zeolites was noted about 250 years ago, this mineral was not studied in depth until 1940 with the pioneering studies of Professor Barrer and coworkers in zeolite synthesis and adsorption. ${ }^{1}$ Today, more than 200 different structural types of zeolites are known, the majority being synthetic. All these structures have been formally recognized by the Structure Commission of the International Zeolite Association $(I Z A)^{5}$ and assigned a three-letter code, the so-called Framework Type Code. ${ }^{1}$

Zeolites are microporous crystalline aluminosilicates, which belong to the family of the tectosilicates. These materials are constituted by a framework structure composed of $\mathrm{TO}_{4}$ tetrahedra $(\mathrm{T}=\mathrm{Si}, \mathrm{Al}$ ) interconnected through $\mathrm{O}$ atoms. ${ }^{2}$ For a purely siliceous structure, the combination of $\mathrm{TO}_{4}(\mathrm{~T}=\mathrm{Si})$ units leads to silica $\left(\mathrm{SiO}_{2}\right)$, with a complete charge balance within the structure. ${ }^{2}$ Nevertheless, when Al atoms are incorporated into the silica framework, the +3 
charge on the Al makes the zeolite framework negatively charged, due to difference between the $\left(\mathrm{AlO}_{4}\right)^{5-}$ and $\left(\mathrm{SiO}_{4}\right)^{4-}$ tetrahedral. ${ }^{2,3}$ This negative charge requires the presence of inorganic or organic cations within the structure to keep the overall framework neutral ${ }^{1-3}$ (Fig. 1).

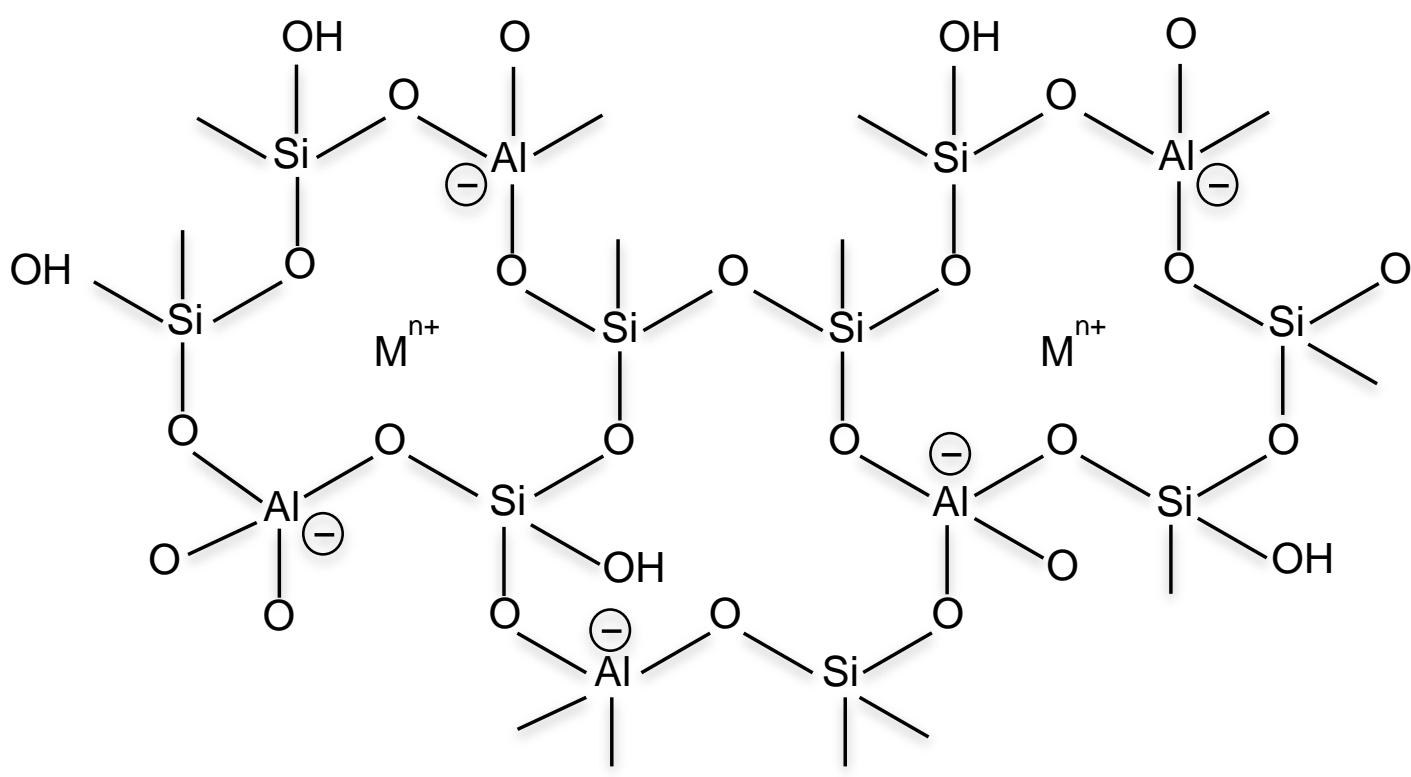

Fig. 1. Two-dimensional representation of the framework structure of zeolites. "Reprinted (adapted) from Ref. ${ }^{3}$, Copyright (2006), with permission from Elsevier".

The zeolite structure is made up of three components: the aluminosilicate framework $\left[\mathrm{Al}_{\mathrm{x}} \mathrm{Si}_{1-\mathrm{x}} \mathrm{O}_{2}\right]$, extraframework or exchangeable cations $\left(\mathrm{M}_{\mathrm{x} / \mathrm{n}}{ }^{\mathrm{n}}\right)$ and water $\left(y \mathrm{H}_{2} \mathrm{O}\right)$. The simplified formula of aluminosilicate zeolites is $\mathrm{M}_{x / n}{ }^{\mathrm{n}+}\left[\mathrm{Al}_{\mathrm{x}} \mathrm{Si}_{1}\right.$ $\left.{ }_{x} \mathrm{O}_{2}\right] \cdot y \mathrm{H}_{2} \mathrm{O}$, where $\mathrm{x}$ can vary from $0-0.5, y$ represents water molecules and $\mathrm{M}^{\mathrm{n}+}$ can be either inorganic or organic cation. ${ }^{2,6}$ Inorganic cations are usually alkaline or alkaline earth, and organic cations could be alkylammonium. These extraframework cations are ion exchangeable and give rise to the rich ionexchange chemistry of these materials. ${ }^{2,3}$ The water and organic non- 
framework cations can be easily removed by a thermal treatment/oxidation, making the intracrystalline space fully accesible. ${ }^{2}$

The amount of $\mathrm{Al}$ within the framework can vary over a wide range, with the Si/Al ratio ranging from 1 to $\infty .{ }^{2}$ Lowenstein proposed that the lower limit of $\mathrm{Si} / \mathrm{Al}$ in a zeolite framework of 1 arises because placement of adjacent $\left(\mathrm{AlO}_{4}\right)^{5-}$ tetrahedra is not favored because of electrostatic repulsions between negative charges. ${ }^{2}$ The framework composition depends on the synthesis conditions. Post-synthesis modifications to insert $\mathrm{Si}$ or Al into the framework have also been developed. The composition of zeolites, especially the Si/Al ratio, determines their properties and often is limited by the framework type itself. As the Si/Al ratio of the framework increases, the hydrothermal stability as well as the hydrophobicity increases. ${ }^{2}$ Purely siliceous zeolites were reported, although most of them contain Al at ppm or ppb levels. ${ }^{1}$ High-silica zeolites present Si/Al ratios higher than 5, although zeolites with Si/Al ratios from 10 to 100 have been reported. ${ }^{2}$ Even though the Al content is low, these zeolites manifest acidity. An example of a high-silica zeolite is the synthetic ZSM-5 (ratio Si/Al>15). Intermediate silica zeolites present a Si/AI ratio between 2 and 5. For example, $\mathrm{Y}$ zeolite belongs to this group of zeolites. ${ }^{2}$ Usually, a larger Al content means greater overall acidity but sometimes it is offset by lowered stability. ${ }^{1}$ The Si/Al ratio of low-silica or Al-rich zeolites is less than 2. Most zeolites found in nature are of lower Si/Al ratios such as $A$ and $X$ zeolites (ratios Si/Al between 1.0-1.5). Due to their high Al content, these zeolites have the highest cation contents and are excellent ion-exchange agents. ${ }^{2}$

Tetrahedra are the primary building units of zeolites, but the frameworks can also be considered in terms of secondary building units, which are networks 
of tetrahedra linked through oxygen bridges. ${ }^{6}$ The combination of tetrahedra in $3 \mathrm{D}$ results in a large variety of rings that are responsible for the cages, cavities and pore windows within the framework of the zeolites. Fig. 2 shows two schematic structures of important zeolites and the representation of their primary porous system.

Structure
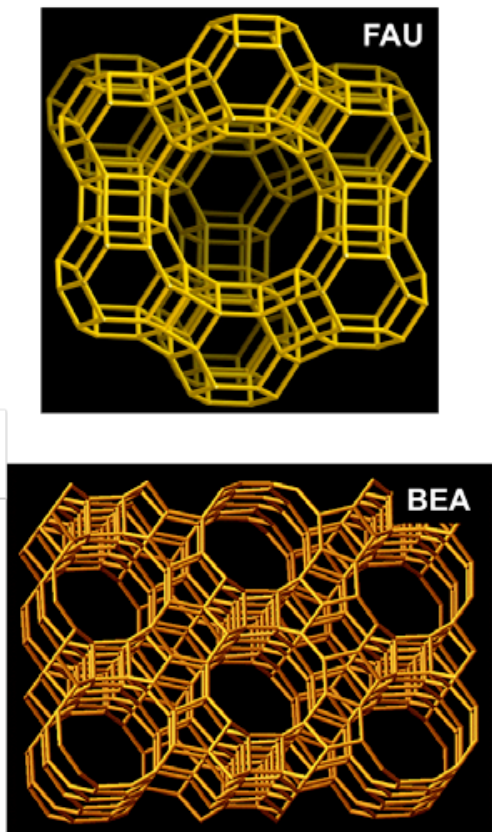

Pore
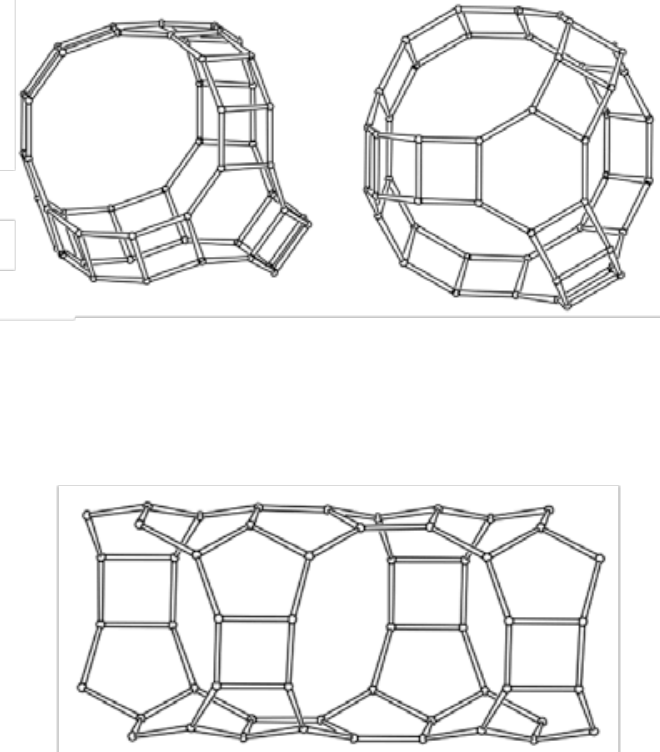

Fig. 2. Schematic structures of the FAU and BEA zeolites, and the representation of their primary pore system. Source: figures obtained from IZA webpage. $^{5}$

Zeolite structures are described in terms of pore size, geometry and connectivity/dimensionality of the pore space. ${ }^{6}$ The internal volume of zeolites consists of interconnected cages or channels, which can be from 1D to $3 \mathrm{D} .^{2}$ The measure of the pore size is in terms of the number ' $n$ ' of T atoms in the circumference of the channel, defined as the 'n-ring' or nMR. ${ }^{1}$ Zeolites with channels or pore openings (windows) described by planar 6MRs or less have 
pore sizes around $2 \AA$, those with planar $8 \mathrm{MR}$ windows or channels have pore sizes around $4 \AA$ and are known as small-pore, those with planar 10MR windows or channels as medium-pore $(5.5 \AA)$ and those with planar $12 \mathrm{MR}$ windows or channels as large-pore $(7.5 \AA){ }^{6}$ There are also zeolites with pore openings limited by $14 \mathrm{MRs}$ or $18 \mathrm{MRs}$ or more, these are known as extra-largepore solids. ${ }^{6}$ Fig. 3 shows pore sizes of different zeolite frameworks.

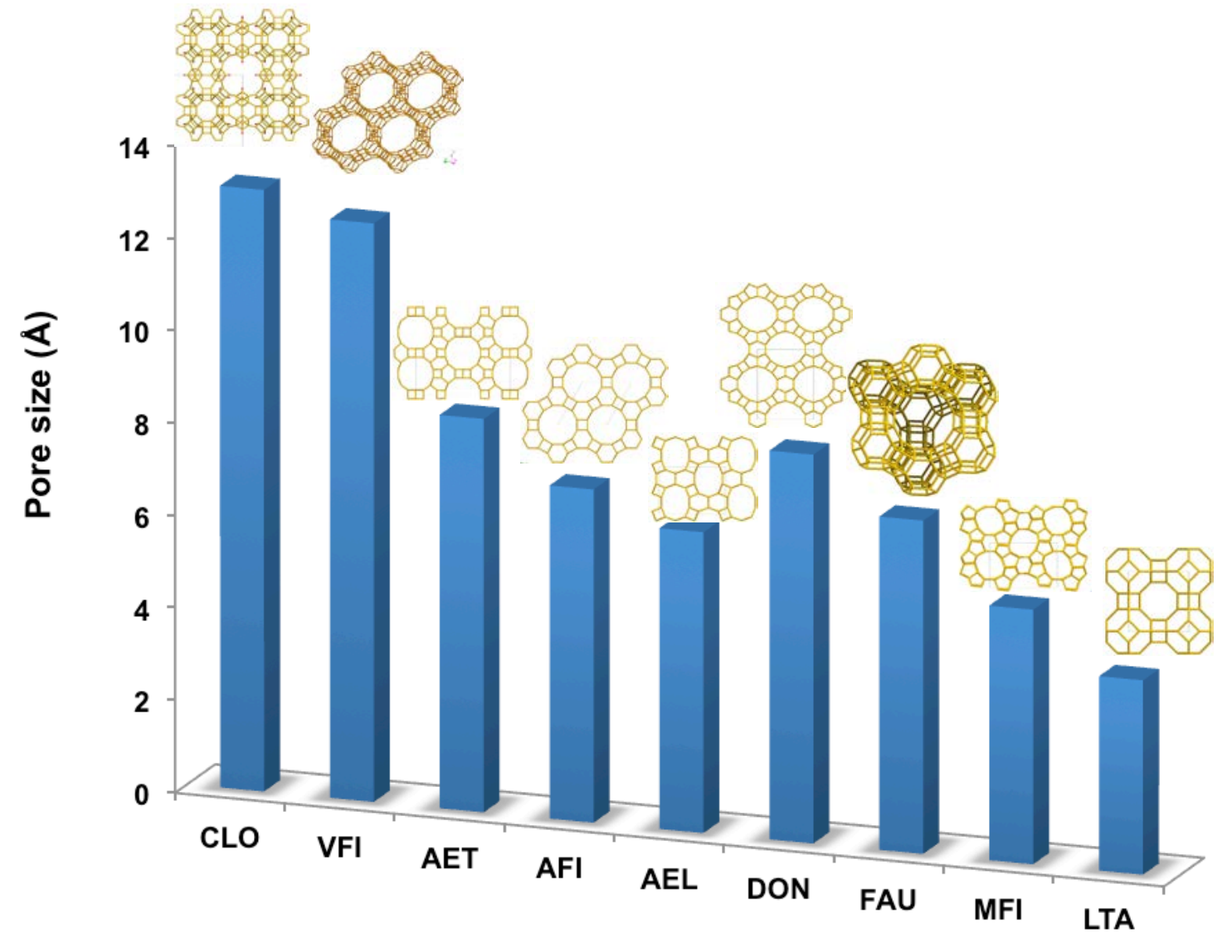

Zeolite frameworks

Fig. 3. Comparison of the pore size of different zeolites framework structures. CLO, Cloverite; VFI, VPI-5; AET, AIPO-8; AFI, AIPO-5; AEL, AIPO-11; DON, UTD-1F; FAU, Faujasite; MFI, ZSM-5; LTA, Linde Type A. "Reprinted (adapted) with permission from Ref. ${ }^{2}$. Copyright (2003) American Chemical Society". 
Natural zeolites possess medium or large pores with low Si/Al ratios, however some of their synthetic analogs were prepared with more silicon, resulting in extra-large pores. Due to the above, zeolites have the capacity to discriminate molecules with dimensional differences less than $1 \AA$, according to their size and shape. For this reason, zeolites are known as molecular sieves. ${ }^{2}$ On the other hand, zeolites present an internal surface, which is highly accessible and can compose more than $98 \%$ of the total surface area, being the later around $300-700 \mathrm{~m}^{2} \mathrm{~g}^{-1}$. Low-silica zeolites are hydrophilic and unstable in acid, whereas high-silica zeolites are stable in boiling mineral acids, unstable in basic solution and hydrophobic. Thermal stability of zeolites varies according to Si/Al ratio, for low-silica zeolites the decomposition temperature is around 700 ${ }^{\circ} \mathrm{C}$, whereas for purely siliceous zeolites is approximately $1300{ }^{\circ} \mathrm{C}{ }^{2}$ Their catalytic action is due to their strongly acidic nature: the terminal hydroxyl groups in the framework are considered Brönsted-acid sites and the interaction of hydroxyl oxygen with a $\mathrm{T}$ atom produces Lewis-acid sites. ${ }^{3}$ Cation concentration, siting, and exchange selectivity also depend on Si/Al ratios. ${ }^{2}$ Their ability to exchange one cation for another is known as their "cationexchange capacity" or "CEC". Total CEC in natural zeolites vary from 0.25 to 3 meq $g^{-1} .4$

Zeolites, as described above, are of great interest because their ordered microporous structures combined with high surface area, ion-exchange capacity, thermal and chemical stability, and other beneficial qualities as their low cost of obtaining from natural sources or synthesis, their availability in great amounts and their simple modification to get the desired physical and chemical properties. ${ }^{3}$ Additionally, the ability of zeolites to discriminate molecules based 
on their size or shape expands the concept of molecular sieving and in more detail the so-called shape selectivity. Therefore, zeolites are of great interest for many applications with significant commercial impact ${ }^{1-4}$ in different fields such as catalysis, petrochemistry, environmental remediation and medicine, among others. More specifically, zeolites have been used as selective adsorbents and ion-exchangers for environmental soil remediation, agriculture, horticulture, malodors control, but their primary use has been in water and wastewater treatment of both organic compounds and heavy-metal ions..$^{3,7}$ In 2006, Granda Valdés et al. ${ }^{3}$ revised some important analytical applications of zeolites mainly in the field of sensors employing zeolite-based electrodes for inorganic and organic compounds determination or sensors to detect gases, and they briefly discussed some works related with separation and preconcentration methodologies. ${ }^{3}$ Up to date, the number of publications about applications of zeolites in Analytical Chemistry has increased, but it is still scarce considering the excellent possibilities offered by these materials. Therefore, the aim of this work is reviewing extraction and microextraction techniques such as solidphase microextraction (SPME), magnetic solid-phase extraction (MSPE) and dispersive solid-phase extraction (DSPE), among others, where zeolites and zeolite-based materials have been used as extractant phases for inorganic and organic compounds determination.

\section{Zeolites and zeolite-based materials in extraction and}

\section{microextraction techniques}

Every analytical chemist knows that "the best sample preparation is the one that does not exist", however, it is considered a utopia because samples usually 
need to be adapted to the measurement instrument. ${ }^{8}$ Sample preparation has always been considered the Achilles heel of the analytical procedure due to its drawbacks such as tediousness, high degree of manipulation, risk of losses and contamination, the employment of large amounts of sample, solvents and sorbents, and therefore, generation of large amounts of wastes. ${ }^{8}$ For this reason, many efforts in recent decades have been focused on the reduction of this negative impact over the analytical procedure. ${ }^{8}$ Nowadays, there are many sample preparation strategies available for these purposes, being solid-phase extraction (SPE) ${ }^{9}$ one of the most commonly employed technique for many years. However, this technique presents some of the classical disadvantages of sample preparation such as large volumes of toxic organic solvents and samples, high degrees of sample manipulation and sorbents are limited, among others. For the reasons described above, this technique has been replaced in the last two decades by its miniaturized technique, SPME, ${ }^{10}$ maintaining their advantages and reducing or eliminating most of the drawbacks. One of the main limitations of SPE and SPME techniques is the reduced number of sorbents, therefore, zeolites and zeolites-based materials are an excellent alternative to replace the conventional sorbents.

Raw zeolites act mainly as cation-exchange materials, and therefore, the first application in 1999 was focused on the use of a zeolite as extractant material for metals determination. ${ }^{11}$ The cation-exchange property mainly depends on the Si/Al ratio, where low ratios favor this kind of interactions. Otherwise, high Si/Al ratios reduce the hydrophilic character and the cationexchange capacity, allowing the adsorption of organic molecules. ${ }^{4}$ However, even at high Si/Al ratios the adsorption of anions or organic molecules is low. 
Regarding to this, zeolite adsorption properties can be easily modified through different paths. Firstly, the main modification to increase the extraction of organic molecules is the treatment with surfactants, mainly cationic such as cetyltrimethylammonium bromide, sodium dodecyl sulfate or tetradecyldimethylbenzylammonium chloride, to increase the hydrophobic interactions. ${ }^{12,13}$ The modification is easily achieved by exchanging the cation of the zeolite by the cation of the surfactant. Additionally and after the surfactant modification, the zeolite can be further modified with a chelating agent, being immobilized on the cationic surface to increase the metal affinity. ${ }^{14,15}$ Another significant modification is the decoration of the zeolites with iron oxide (i.e., $\mathrm{Fe}_{3} \mathrm{O}_{4}$ or $\mathrm{Fe}_{2} \mathrm{O}_{3}$ ) nanoparticles to provide paramagnetic properties. ${ }^{16-20}$ Magnetic sorbents are widely used nowadays in (micro)extraction techniques due to the easy handling of the sorbent avoiding filtration or centrifuges for phases separation, doing the extraction procedure more environmentally friendly and portable for on-site extractions. For example, in dispersive (micro)extraction techniques the phases separation is carried out with an external magnetic field (i.e., Neodymium (Nd) magnet). ${ }^{18,20}$

Zeolites commonly used in extraction and microextraction techniques are summarized in Table 1. Zeolites have been used as raw materials or modified mainly with surfactants, chelating agents, metals and/or metallic particles. 
Table 1. Properties of the most commonly used zeolites in extraction and microextraction techniques.

\begin{tabular}{|c|c|c|c|c|c|c|}
\hline Zeolite & Chemical formula & IZA code & $\begin{array}{c}\text { Channel } \\
\text { dimensionality }\end{array}$ & $\begin{array}{c}\text { Pore } \\
\text { opening }\end{array}$ & Pore dimensions $/ \AA$ & Ref. \\
\hline Phillipsite & {$\left[\mathrm{K}_{2}^{+}\left(\mathrm{Ca}^{2+}, \mathrm{Na}_{2}^{+}\right)_{2}\left(\mathrm{H}_{2} \mathrm{O}\right)_{12}\right]\left[\begin{array}{ll}\mathrm{Al}_{6} \mathrm{Si}_{10} \mathrm{O}_{32}\end{array}\right]$} & $\mathrm{PHI}$ & $3 \mathrm{D}$ & $8 \times 8 \times 8$ & $3.8 \times 3.8 ; 3.0 \times 4.3 ; 3.2 \times 3.3$ & 21,22 \\
\hline Mordenite & {$\left[\mathrm{Na}_{8}^{+}\left(\mathrm{H}_{2} \mathrm{O}\right)_{24}\right]\left[\begin{array}{lll}\mathrm{Al}_{8} \mathrm{Si}_{40} \mathrm{O}_{96} & \end{array}\right.$} & MOR & $2 \mathrm{D}$ & $12 \times 8$ & $6.5 \times 7.0 ; 2.6 \times 5.7$ & 11,23 \\
\hline Clinoptilolite & {$\left[\mathrm{Ca}_{4}^{2+}\left(\mathrm{H}_{2} \mathrm{O}\right)_{24}\right]\left[\mathrm{Al}_{8} \mathrm{Si}_{28} \mathrm{O}_{72}\right]$} & HEU & $2 \mathrm{D}$ & $10 \times 8$ & $3.1 \times 5.5+4.1 \times 4.1 ; 2.8 \times 3.4$ & $16,24-34$ \\
\hline ZSM-5 & {$\left[\mathrm{Na}_{\mathrm{n}}^{+}\left(\mathrm{H}_{2} \mathrm{O}\right)_{16}\right]\left[\mathrm{Al}_{\mathrm{n}} \mathrm{Si}_{96-\mathrm{n}} \mathrm{O}_{192}\right], \mathrm{n}<27$} & MFI & $3 \mathrm{D}$ & $10 \times 10$ & $5.1 \times 5.5 ; 5.3 \times 5.6$ & $17,18,20,35,36$ \\
\hline $\mathrm{L}$ & {$\left[\mathrm{K}_{6}^{+} \mathrm{Na}_{3}^{+}\left(\mathrm{H}_{2} \mathrm{O}\right)_{21}\right]\left[\mathrm{Al}_{9} \mathrm{Si}_{27} \mathrm{O}_{72}\right]$} & LTL & $3 \mathrm{D}$ & 12 & $7.1 \times 7.1$ & 37 \\
\hline$X$ & {$\left[\left(\mathrm{Ca}^{2+}, \mathrm{Mg}^{2+} \mathrm{Na}^{+}{ }_{2}\right)_{29}\left(\mathrm{H}_{2} \mathrm{O}\right)_{240}\right]\left[\begin{array}{ll}\mathrm{Al}_{58} \mathrm{Si}_{134} & \mathrm{O}_{384}\end{array}\right]$} & FAU & $3 \mathrm{D}$ & 12 & $7.4 \times 7.4$ & $38-40$ \\
\hline Analcime & {$\left[\mathrm{Na}^{+}{ }_{16}\left(\mathrm{H}_{2} \mathrm{O}\right)_{16}\right]\left[\mathrm{Al}_{16} \mathrm{Si}_{32} \mathrm{O}_{96}\right]$} & ANA & $3 \mathrm{D}$ & - & - & $14,15,41-46$ \\
\hline Y & {$\left[\left(\mathrm{Ca}^{2+}, \mathrm{Mg}^{2+} \mathrm{Na}^{+}{ }_{2}\right)_{29}\left(\mathrm{H}_{2} \mathrm{O}\right)_{240}\right]\left[\begin{array}{ll}\mathrm{Al}_{58} \mathrm{Si}_{134} & \mathrm{O}_{384}\end{array}\right]$} & FAU & $3 \mathrm{D}$ & 12 & $7.4 \times 7.4$ & $13,19,47-51$ \\
\hline Natrolite & {$\left[\mathrm{Na}^{+}{ }_{16}\left(\mathrm{H}_{2} \mathrm{O}\right)_{16}\right]\left[\begin{array}{ll}\mathrm{Al}_{16} \mathrm{Si}_{24} \mathrm{O}_{80}\end{array}\right]$} & NAT & $3 \mathrm{D}$ & $9 \times 8$ & $2.5 \times 4.1 ; 2.6 \times 3.9$ & 46,52 \\
\hline A & {$\left[\mathrm{Na}^{+}{ }_{12}\left(\mathrm{H}_{2} \mathrm{O}\right)_{27}\right]_{8}\left[\mathrm{Al}_{12} \mathrm{Si}_{12} \mathrm{O}_{48}\right]_{8}$} & LTA & $3 \mathrm{D}$ & 8 & $4.1 \times 4.1$ & $35,40,51,53$ \\
\hline Beta & 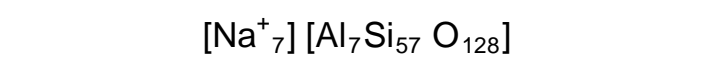 & BEA & $3 \mathrm{D}$ & $12 \times 12$ & $6.6 \times 6.7 ; 5.6 \times 5.6$ & $54-57$ \\
\hline
\end{tabular}


The review has been organized based on the use of zeolites and zeolite-based materials for the extraction of organic (Section 3) or inorganic compounds (Section 4). Both Sections are divided in the different extraction and/or microextraction techniques that employ these materials as extractant phases (Fig. 4). As shown in Fig. 4, the extractant phase configurations available for the extraction of organic compounds are more diverse than those employed for metals extraction.

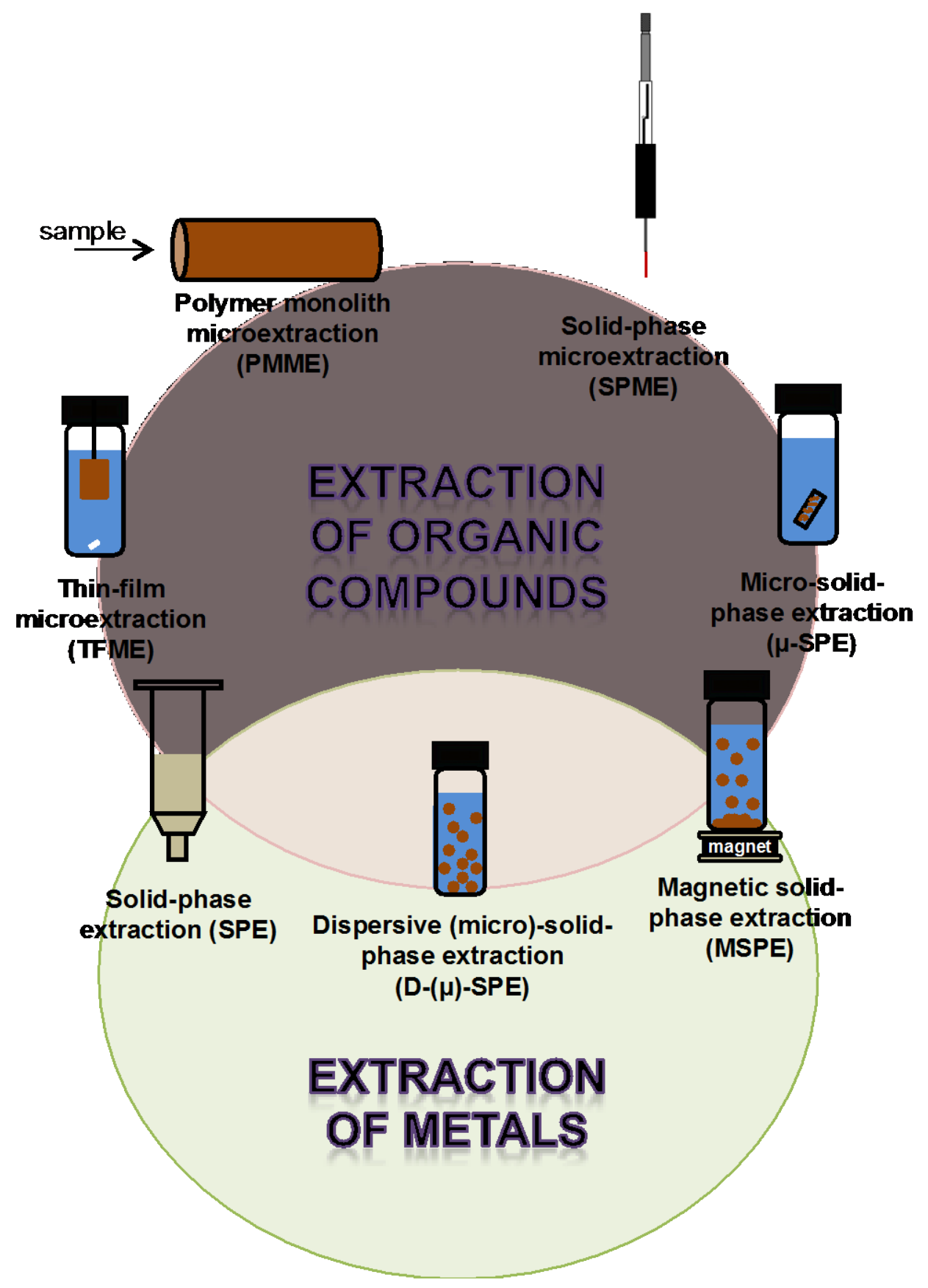


Fig. 4. Scheme of the extraction and microextraction techniques that employ zeolites or zeolite-based materials for the extraction of organic compounds and metals.

\section{Extraction of organic compounds}

Solid-phase extraction and microextraction techniques are widely employed in sample preparation providing analyte isolation, preconcentration and sample clean-up. ${ }^{9}$ The study of different sorbents that improve extraction yields and selectivity towards target analytes has been a recurrent issue in numerous publications. ${ }^{58-62}$ Among the proposed sorbents (e.g., ionic liquids, molecularly imprinted polymers, carbon nanomaterials), zeolites have been presented as a valuable alternative to separate and preconcentrate organic analytes from different matrices prior to instrumental analysis. Table 2 summarizes the analytical methods discussed in this section based on the extraction of organic compounds using zeolites and zeolite-based materials as sorbents. 
Table 2. Extraction of organic compounds using zeolite and zeolite-based materials as sorbents.

\begin{tabular}{|c|c|c|c|c|c|c|}
\hline Sorbent & Analyte & Sample & Extraction technique: conditions & $\begin{array}{c}\text { Separation/detection } \\
\text { technique }\end{array}$ & $\begin{array}{l}\text { LOD } \\
\left(\mu \mathrm{g} \mathrm{L}^{-1}\right)\end{array}$ & Ref. \\
\hline $\begin{array}{l}\text { Microemulsion modified natural } \\
\text { zeolite (major mineral: phillipsite, } \\
\text { minor mineral: fassaite) }\end{array}$ & $\begin{array}{l}\text { Sulphonated and azo } \\
\text { sulphonated dyes }\end{array}$ & Textil wastewater & $\begin{array}{l}\text { SPE: polyethylene column packed with } 1 \mathrm{~g} \text { of modified zeolite, } 100-250 \\
\mathrm{~mL} \text { of sample at } \mathrm{pH}=7 \text {, elution with } 5 \mathrm{~mL} \text { methanol/water }(70: 30 \mathrm{v} / \mathrm{v})\end{array}$ & $\begin{array}{l}\text { UV-vis } \\
\text { spectrophotometry }\end{array}$ & $15-25^{a}$ & 21 \\
\hline $\begin{array}{l}\text { Natural zeolite (major mineral: } \\
\text { phillipsite, minor mineral: fassaite) }\end{array}$ & Cationic dyes & Stream water & $\begin{array}{l}\text { SPE: polyethylene tube packed with } 0.3 \mathrm{~g} \text { of zeolite, } 1 \mathrm{~L} \text { of sample at } \\
\qquad \mathrm{pH}=5 \text {, elution with } 10 \mathrm{~mL} 0.02 \mathrm{M} \mathrm{HNO}_{3}\end{array}$ & $\begin{array}{l}\text { UV-vis } \\
\text { spectrophotometry }\end{array}$ & $43-245^{b}$ & 22 \\
\hline CTA modified NaY zeolite & Carbamate pesticides & $\begin{array}{l}\text { Rice filed, } \\
\text { underground, tap and } \\
\text { waste water }\end{array}$ & $\begin{array}{l}\text { SPE: cartridge packed with } 100 \mathrm{mg} \text { of zeolite, on-line modification with } \\
\text { CTA, extraction } 20 \mathrm{~mL} \text { of sample, elution with } 750 \mu \mathrm{L} \text { of methanol }\end{array}$ & LC-UV & $0.005-140^{c}$ & 13 \\
\hline AChE-immobilized beta zeolite & AChE binders & $\begin{array}{l}\text { Crude extract of } \\
\text { Corydalis yanhusuo }\end{array}$ & $\begin{array}{l}\text { SPE: sample solution incubated with } 0.025 \mathrm{mg} \text { AChE modified zeolite at } \\
37^{\circ} \mathrm{C} \text { for } 20 \mathrm{~min} \text {, elution with } 20 \mathrm{~mL} \text { of } 50 \%(\mathrm{v} / \mathrm{v}) \text { methanol/water }\end{array}$ & UPLC-Q-TOF-MS & $293^{c}$ & 54 \\
\hline $\begin{array}{l}\text { Natural clinoptilolite, TMA and } \\
\text { ODTMA modified natural } \\
\text { clinoptilolites }\end{array}$ & Zearalenone & Beer & $\begin{array}{c}\text { DSPE: } 200 \mathrm{mg} \text { of sorbent, } 100 \mathrm{~mL} \text { of sample at } \mathrm{pH}=4.3 \text {, extraction for } 30 \\
\text { min, filtration, elution with } 5 \mathrm{~mL} \text { of ethanol for } 30 \mathrm{~min}\end{array}$ & LC-FD & $20^{d}$ & 24 \\
\hline PANI modified NaY zeolite & Pesticides & $\begin{array}{l}\text { Fruits, vegetables and } \\
\text { water }\end{array}$ & $\begin{array}{l}\text { DSPE: } 150 \mathrm{mg} \text { of sorbent in } 125 \mathrm{~mL} \text { sample }(\mathrm{pH}=8) \text {, extraction for } 4 \mathrm{~min} \text {, } \\
\text { transfering the sorbent to a SPE elution column, removing interferences } \\
\text { with water, elution of analytes with } 3 \mathrm{~mL} \text { of } 0.01 \mathrm{M} \mathrm{NaOH} \text { in } 90 \% \\
\text { acetonitrile }\end{array}$ & HPLC-PDA & $1-1000^{c}$ & 47 \\
\hline Natural zeolite & $\begin{array}{r}\text { Ketonic } \\
\text { bodies }\end{array}$ & Urine & $\begin{array}{c}\text { SPME: HS mode, } 5 \mathrm{~mL} \text { of sample at } 30^{\circ} \mathrm{C} \text {, extraction for } 15 \mathrm{~min} \text {, } \\
\text { thermal desorption at } 250^{\circ} \mathrm{C}\end{array}$ & GC-FID & $300-600^{c}$ & 63 \\
\hline Natural zeolite & BTEX & Water and soil & $\begin{array}{l}\text { SPME: HS mode, } 10 \mathrm{~mL} \text { of water samples at } 25^{\circ} \mathrm{C} \text { or } 2 \mathrm{~g} \text { of soil } \\
\text { samples sonicated at } 40^{\circ} \mathrm{C} \text {, extraction for } 30 \text { min (water samples) or } 25 \\
\text { min (soil samples), thermal desorption at } 250^{\circ} \mathrm{C}\end{array}$ & GC-FID & $0.66-1.66^{c}$ & 64 \\
\hline LTA zeolite vs ZSM-5 zeolite & $\begin{array}{l}\text { Organophosphate } \\
\text { neurotoxins }\end{array}$ & $\begin{array}{l}\text { Sea and river water } \\
\text { and synthetic urine }\end{array}$ & $\begin{array}{c}\text { SPME: DI mode, } 10 \mu \mathrm{L} \text { of rain water }(\mathrm{pH}=6) \text {, seawater }(\mathrm{pH}=8) \text { and } \\
\text { synthetic urine }(\mathrm{pH}=6) \text {, extraction for } 1 \text { min }\end{array}$ & Low temperature plasma MS & $24.46-98.89^{\mathrm{a}}$ & 35 \\
\hline LTL zeolite & Ochratoxin A & Coffee and cereal & $\begin{array}{c}\mu \text {-SPE: } 25 \mathrm{mg} \text { packed zeolite, } 10 \mathrm{~mL} \text { of sample at } \mathrm{pH}=1.5, \text { extraction for } \\
40 \mathrm{~min} \text {, elution with } 400 \mu \mathrm{L} \text { of methanol }\end{array}$ & LC-FD & $\begin{array}{l}0.03-0.09^{\mathrm{a}} \\
\left(\mathrm{ng} \mathrm{g}^{-1}\right)\end{array}$ & 37 \\
\hline ZSM-5/Tenax TA & VOCs & Aqueous standards & $\begin{array}{l}\text { TFME: HS and DI modes, } 15 \mathrm{~mL} \text { of sample at RT, extraction for } 30 \mathrm{~min} \text {, } \\
\text { thermal desorption at } 220^{\circ} \mathrm{C} \text { with He stream }\end{array}$ & GC-MS & $\begin{array}{l}12^{\mathrm{e}} \text { (benzene) } \\
13^{\mathrm{e}} \text { (toluene) }\end{array}$ & 36 \\
\hline
\end{tabular}




\begin{tabular}{|c|c|c|c|c|c|c|}
\hline Synthetic zeolite & $\begin{array}{l}\text { Synthetic } \\
\text { colorants }\end{array}$ & Red lipsticks & $\begin{array}{c}\text { PMME: } 5 \mathrm{mg} \text { of modified zeolite, } 1.2 \mathrm{~mL} \text { of sample at } \mathrm{pH}=3 \text {, elution with } \\
0.5 \% \text { ammonia solution/methanol }(1: 1, \mathrm{v} / \mathrm{v})\end{array}$ & LC-MWD & $1.3-3.7^{c}$ & 65 \\
\hline $\begin{array}{l}\text { Lantanum(III) modified natural } \\
\text { clinoptilolite }\end{array}$ & Hemoglobin & Blood & $\begin{array}{l}\mathrm{D}-\mu \text {-SPE: } 10 \mathrm{mg} \text { of sorbent, } 500 \mu \mathrm{L} \text { of sample at } \mathrm{pH}=5 \text {, extraction for } 30 \\
\text { min, centrifugation for } 5 \mathrm{~min} \text { at } 2000 \text { rpm, elution with } 500 \mu \mathrm{L} \text { of } 0.01 \mathrm{M} \\
\qquad \mathrm{Na}_{3} \mathrm{PO}_{4} \text { for } 10 \mathrm{~min}\end{array}$ & SDS-PAGE & $-f$ & 25 \\
\hline Natural mordenite & Creatinine & $\begin{array}{l}\text { PBS and PBS with } \\
\text { albumin solutions }\end{array}$ & $\begin{array}{c}\mathrm{D}-\mu \text {-SPE: } 2 \mathrm{~mL} \text { of sample } / 40 \mathrm{mg} \text { of sorbent, extraction for } 12 \mathrm{~h} \text { at } 37^{\circ} \mathrm{C} \text {, } \\
\text { centrifugation, drying of solid sorbent at } 37^{\circ} \mathrm{C} \text { for } 1 \mathrm{~h}\end{array}$ & DR-UV & $\mathrm{ft}^{\mathrm{t}}$ & 66 \\
\hline BEA zeolite & PAHs & Tap and lake water & $\begin{array}{c}\text { D- } \mu \text {-SPE: } 2 \mathrm{mg} \text { of zeolite, } 1 \mathrm{~mL} \text { of sample, extraction for } 1 \mathrm{~min}, \\
\text { centrifugation for } 5 \mathrm{~min} \text { at } 13400 \mathrm{rpm} \text {, elution with } 100 \mu \mathrm{L} \text { of } \\
\text { methanol/water }(70: 30, \mathrm{v} / \mathrm{v}) \text { for } 5 \mathrm{~min}\end{array}$ & LC-UV/FD & $0.0011-0.0499^{a}$ & 55 \\
\hline BEA zeolite & PAHs & Tap and lake water & $\begin{array}{l}\text { D- } \mu \text {-SPE: } 2 \mathrm{mg} \text { of zeolite, } 1 \mathrm{~mL} \text { of sample, extraction for } 1 \mathrm{~min} \text {, } \\
\text { centrifugation for } 5 \mathrm{~min} \text { at } 13400 \mathrm{rpm} \text {, elution with } 100 \mu \mathrm{L} \text { of } \\
\text { methanol/water }(70: 30, \mathrm{v} / \mathrm{v}) \text { for } 5 \mathrm{~min} \text {, addition of } 100 \mu \mathrm{L} \text { of octane }\end{array}$ & LETRSS & $0.0011-0.194^{a}$ & 56 \\
\hline CTA modified NaY zeolite & Carbamate pesticides & $\begin{array}{l}\text { Fruits, vegetables and } \\
\text { surface water }\end{array}$ & $\begin{array}{l}\mathrm{D}-\mu \text {-SPE: } 40 \mathrm{mg} \text { of sorbent, } 7 \mathrm{~mL} \text { of sample, vortex-assisted extraction } \\
\text { for } 2 \mathrm{~min} \text {, filtration, elution with } 500 \mu \mathrm{L} \text { of methanol }\end{array}$ & LC-PDA & $\begin{array}{l}0.004-4.000^{\mathrm{c}} \\
\left(\mathrm{mg} \mathrm{Kg}^{-1}\right)\end{array}$ & 48 \\
\hline Natural clinoptilolite/ $\mathrm{Fe}_{3} \mathrm{O}_{4}$ & Phthalates & Mineral water & $\begin{array}{c}\text { MSPE: } 80 \mathrm{mg} \text { of sorbent, } 10 \mathrm{~mL} \text { of sample, vortex-assisted extraction for } \\
16 \text { min, elution with } 4 \mathrm{~mL} \text { of acetone for } 8 \mathrm{~min}\end{array}$ & GC-FID & $2.80-3.20^{d}$ & 16 \\
\hline $\begin{array}{l}\text { CC[4]A modified magnetic ZSM-5 } \\
\text { zeolite }\end{array}$ & $\begin{array}{l}\text { Phenolic } \\
\text { antioxidants }\end{array}$ & $\begin{array}{l}\text { Juice and infant milk } \\
\text { powder }\end{array}$ & $\begin{array}{l}\text { MSPE: } 30 \mathrm{mg} \text { of sorbent, } 100 \mathrm{~mL} \text { of sample at } \mathrm{pH}=3 \text {, ultrasound- } \\
\text { assisted extraction for } 10 \mathrm{~min} \text {, elution with } 1 \mathrm{~mL} \text { of methanol }\end{array}$ & LC-UV & $6.0-67.5^{\mathrm{a}}$ & 17 \\
\hline ZSM-5/iron oxide & BTEX & $\begin{array}{l}\text { Industrial wastewater, } \\
\text { drinking and river } \\
\text { water }\end{array}$ & $\begin{array}{l}\text { MSPE: } 138 \mathrm{mg} \text { of sorbent, } 22 \mathrm{~mL} \text { of sample, manual agitation for } 11 \mathrm{~min} \text {, } \\
\text { elution with } 0.5 \mathrm{~mL} \text { of acetone for } 5 \mathrm{~min}\end{array}$ & GC-MS & $0.3-3^{a}$ & 18 \\
\hline Hydrophobic silica zeolite & BTX & Indoor air & $\begin{array}{c}\text { Passive sampling in controlled atmosphere and real environments, } \\
\text { thermal desorption at } 300^{\circ} \mathrm{C} \text { for } 30 \mathrm{~min}\end{array}$ & GC-MS & $\begin{array}{c}6.1-11^{g} \\
\left(\mu g \mathrm{~m}^{-3} \text { for } 24 \mathrm{~h}\right. \\
\text { exposure) }\end{array}$ & 67 \\
\hline NaX zeolite & Oxygenated solvents & Fire debris & $\begin{array}{l}\text { Heated passive HS extraction, desorption with } 500 \mu \mathrm{L} \text { of methyl ethyl } \\
\text { ketone }\end{array}$ & GC-MS & $-f$ & 39 \\
\hline NaX zeolite and activated charcoal & $\begin{array}{l}\text { Oxygenated solvents } \\
\text { and petroleum } \\
\text { derivatives }\end{array}$ & Fire debris & $\begin{array}{l}\text { Heated passive HS extraction, desorption with methanol (zeolite) or } \mathrm{CS}_{2} \\
\text { (charcoal) }\end{array}$ & GC-MS & $-f^{t}$ & 38 \\
\hline
\end{tabular}

LOD, limit of detection; SPE, solid-phase extraction; UV-vis, ultraviolet-visible; CTA, cetyltrimethylammonium; LC-UV, liquid chromatography-ultraviolet detection; AChE, acetylcholinesterase; UPLCQ-TOF-MS, ultra-high performance liquid chromatography-quadrupole time-of-flight mass spectrometry; TMA, tetramethylammonium; ODTMA, octadecyltrimethylammonium; DSPE, dispersive solidphase extraction; LC-FD, liquid chromatography-fluorescence detection; PANI, polyaniline; HPLC-PDA, high-performance liquid chromatography-photodiode array detection; SPME, solid-phase microextraction; HS, headspace; GC-FID, gas chromatography-flame ionization detection; BTEX, benzene, toluene, ethylbenzene and xylenes; LTA, Linde Type A; ZSM-5, Zeolite Socony Mobil-5; DI, direct immersion; MS, mass spectrometry; LTL, Linde Type L; $\mu$-SPE, micro-solid-phase extraction; VOCs, volatile organic compounds; TFME, thin-film microextraction; RT, room-temperature; 
GC-MS, gas chromatography-mass spectrometry; PMME, polymer monolith microextraction; LC-MWD, liquid chromatography-multiple wavelength detection; D- $\mu$-SPE, dispersive micro-solid-phase extraction; SDS-PAGE, sodium dodecyl sulfate-polyacrylamide gel electrophoresis; PBS, phosphate buffered saline; DR-UV, diffuse reflectance ultraviolet; BEA, beta polymorph A; PAHs, polycyclic aromatic hydrocarbons; LC-UV/FD, liquid chromatography-ultraviolet/fluorescence detection; LETRSS, laser-excited time-resolved Shpol'skii spectroscopy; LC-PDA, liquid chromatographyphotodiode array detection; MSPE, magnetic solid-phase extraction; CC[4]A, carboxylatocalix[4]arenes; BTX, benzene, toluene and xylenes.

${ }^{a}$ Calculated using $3 s_{\text {blank }} / m$, where $s_{\text {blank }}$ is the standard deviation of blank and $m$ is a slope of the calibration curve.

${ }^{\mathrm{b}}$ Estimated using Lorber's method.

${ }^{c}$ Calculated as three times signal-to-noise ratio.

d LOD calculation not mentioned.

e Calculated from the calibration curve cross section for a blank signal.

f LOD not mentioned by the authors.

${ }^{9}$ Calculated as $t_{(n-1,1-a=0.99)} \sigma$, where $t$ is the student's $t$-value for $n-1$ degrees of freedom at $99 \%$ confidence level, and $\sigma$ is the standard deviation of six blank samplers. 


\subsection{Solid-phase extraction}

Typically, solid-phase extraction (SPE) consists of cartridges or columns packed with sorbent where the analyte is retained when liquid samples flow through it. ${ }^{9}$ Then, a proper solvent is employed to elute and recover the analyte for further determination. ${ }^{9}$ Al-Degs et al. ${ }^{21}$ modified a natural zeolite with a microemulsion for the SPE of sulphonated and azo sulphonated dyes from textile wastewater. The microemulsion was based on saponified coconut oil (surfactant), isoamyl alcohol (cosurfactant) and oil phase. The natural zeolite was modified by simply mixing it with the already prepared microemulsion and a final drying step. For SPE, sample solution was passed through a polyethylene column packed with the modified zeolite and then, adsorbed analytes were eluted using a mixture of methanol/water. Thereafter, the concentration of five dyes was determined spectrophotometrically without previous chromatographic separation, using multivariate calibration. It was demonstrated that the microemulsion played a key role in the extraction process since the modified zeolite provided higher enrichment factors than the unmodified zeolite ${ }^{21}$. In addition, the limits of detection (LODs) obtained with the proposed method were similar to those obtained with other sorbents (e.g., $\mathrm{C}_{18}$ columns) and more complex analytical instrumentation (e.g., liquid chromatography-atmospheric pressure ionization mass spectrometry). ${ }^{21}$ In a later publication, the same research group carried out a comparative study about different sorbents (i.e., activated carbon, natural diatomite and natural zeolite) for the SPE of cationic dyes from water samples. ${ }^{22}$ After extraction with the corresponding packed sorbent and elution with a $\mathrm{HNO}_{3}$ solution, five dyes were simultaneously determined by spectrophotometry using multivariate calibration. ${ }^{22}$ Results 
revealed a better performance of diatomite compared to zeolite and the lowest extraction yields were obtained with activated carbon, probably due to stronger interactions with analytes that hindered their release during elution. ${ }^{22}$

The adsorption and desorption of carbamate pesticides in different surfactant-modified sorbents, namely: silica and NaY zeolite coated with cetyltrimethylammonium bromide (CTA-Br) and alumina coated with sodium dodecyl sulfate, was investigated by Arnnok et al. ${ }^{12}$ in a preliminary work for comparative purposes. On one hand, results showed that some pesticides could be adsorbed onto the raw materials (i.e., silica, NaY zeolite and alumina). However, enhancement in sorption of less polar compounds was observed using surfactant-modified sorbents due to the presence of an organic environment of major affinity. ${ }^{12}$ On the other hand, desorption studies using methanol revealed that the analytes release from surfactant-modified sorbents was better than from the unmodified ones. Finally, CTA modified NaY zeolite was selected as the best candidate to act as sorbent for the SPE of carbamate pesticides. $^{12}$ Next, carbamate pesticides were determined in environmental water samples using a flow system that included the on-line zeolite modification with CTA-Br, analytes retention, elution and determination by liquid chromatography-ultraviolet detection (LC-UV). ${ }^{13}$ Although the LODs obtained were generally higher than those obtained in previous publications using commercial sorbents (e.g., $\mathrm{C}_{18}$ ), they were low enough to satisfy the current normative about maximum contaminant limits. ${ }^{13}$ In addition, the proposed online method introduced benefits related to less sample manipulation, short analysis time and low solvent consumption. ${ }^{13}$ 
A new zeolite-based SPE has been recently proposed by Tao et al. ${ }^{54}$ for the extraction of acetylcholinesterase (AChE) binders from crude extract of Corydalis yanhusuo. In a $1.5 \mathrm{~mL}$ centrifuge tube, sample solution was incubated with $0.025 \mathrm{mg}$ AChE modified zeolite at $37^{\circ} \mathrm{C}$ for $20 \mathrm{~min}$. Thereafter, AChEimmobilized zeolite was washed using methanol/water to dissociate specific bound compounds (i.e., AChE binders). Authors named the proposed extraction method as SPE, however the sorbent was not packed within a cartridge or a column, and the described procedure could be more alike other extraction techniques (e.g., dispersive micro-solid-phase extraction). During initial experiments, Y, ZSM-5 and beta zeolites were modified with AChE obtaining the largest percentage of adsorbed AChE and, therefore, the highest extraction capacity by using beta zeolite. In addition, reusability tests proved that the activity of AChE immobilized zeolite was $89 \%$ after 10 cycles, thus providing the advantages of reduced test costs and increased experimental throughput.

Finally, it should be mentioned one publication in which a column loaded with $\mathrm{Y}$ zeolite was employed to remove interfering species from the target analyte (i.e., morphine) in plasma samples ${ }^{68}$ In a previous step, plasma samples were subjected to liquid-phase extraction using tetrahydrofuran as extractant solvent. Then, the extractant phase was passed through the zeolitebased column where unknown compounds (i.e., interferences) were effectively retained and separated from morphine. Thereby, overlapped peaks that initially appeared in the final chromatographic analysis were avoided. 


\subsection{Dispersive solid-phase extraction}

In dispersive solid-phase extraction (DSPE), the solid sorbent is directly introduced and dispersed into the sample solution increasing active surface area and, thereby, enhancing extraction kinetics. ${ }^{69}$ After extraction, extractant phase is normally separated by centrifugation or filtration. Then, analytes can be determined directly on the solid or eluted for the subsequent analysis of the eluated phase. ${ }^{69}$ Pansinli and Henden ${ }^{24}$ investigated natural clinoptilolite and clinoptilolite modified with tetramethylammonium bromide (TMA-Br) or octadecyltrimethylammonium bromide (ODTMA-Br) for the DSPE of zearalenone from beer samples. The studied sorbents were mixed with degassed beer samples and shaken until sorption equilibrium conditions. Later, the mixture was filtrated, sorbent was washed and ethanol was finally added to the solid to elute the analyte. Finally, the ethanol phase was analyzed by liquid chromatography-fluorescence detection (LC-FD). The possibility of reusing the zeolite-based sorbents was investigated, concluding that the three zeolites (i.e., natural clinoptilolite and clinoptilolite modified with TMA-Br or ODTMA-Br) were suitable for six repetitive uses, although a cleaning step for 30 min with $10 \mathrm{~mL}$ of ethanol was necessary between extractions. In the analysis of real samples, low recoveries (i.e., 44-57\%) were obtained using the natural and TMA modified clinoptilolite. On the contrary, recovery reached 90\% with ODTMA modified clinoptilolite showing the effective use of this sorbent to preconcentrate zearalenone from beer samples, probably due to an increase in the hydrophobicity of the zeolite surface. ${ }^{24}$

Polyaniline (PANI) modified NaY zeolite has been investigated by Arnnok et al. ${ }^{47}$ for the extraction of multi-class pesticides from environmental and food 
samples. The modified sorbent was obtained via oxidative polymerization of aniline onto the surface of the NaY zeolite. PANI form can be varied depending on acidity (protonation/deprotonation), thus, various $\mathrm{pH}$ conditions were tested during the synthesis and the resulting modified sorbents were evaluated in order to achieve the highest pesticide sorption capacity. PANI modified NaY zeolite obtained under strong acidic conditions $(\mathrm{pH} 1-2)$ exhibited the best performance upon extraction. ${ }^{47}$ During scanning electron microscopy with energy dispersive spectroscopy (SEM/EDS) analysis, sodium ions and aluminium atoms were not detected on the surface of PANI modified NaY zeolite. This fact revealed that ion exchange between sodium ions on the zeolite surface and anilinium ions occurred during polymerization and, consequently, the zeolite surface was almost completely covered with PANI. ${ }^{47}$ For DSPE, PANI modified NaY zeolite was added to $125 \mathrm{~mL}$ of sample and mechanically shaken to allow sorption of the pesticides onto the sorbent. After that, the suspension was transferred to a polypropylene syringe column serving as a SPE eluting column. Polar interferences (e.g., sugars, salts) were removed with water and, finally, analytes were eluted using a solution of $0.01 \mathrm{M} \mathrm{NaOH}$ in $90 \%$ acetonitrile. Authors compared the capability of PANI modified NaY zeolite for the determination of multi-class pesticides with a commercial $\mathrm{C}_{18}$ sorbent obtaining comparable results, but highlighting the low cost of the proposed sorbent. $^{47}$

All the above mentioned methods employed large amounts of sorbent, solvents and sample (see Table 2), as well as long extraction times. As alternative, new microextraction techniques using zeolites and zeolite-based 
materials as extractant phase were developed, trying to overcome such disadvantages inherent to SPE and DSPE.

\subsection{Solid-phase microextraction}

Solid-phase microextraction (SPME) is based on the extraction of analytes into a fused silica fiber coated with a proper sorbent polymer. ${ }^{10,70,71}$ After extraction in direct immersion (DI) or headspace (HS) modes, analytes are chemically (with low solvent volumes) or thermally desorbed for subsequent determination. Matin et al. ${ }^{63}$ proposed a new SPME fiber based on activated carbon and natural zeolite for the extraction of ketone bodies from urine samples. The extraction of acetone, acetoacetate and $\beta$-hydroxybutyrate was carried out in the HS mode. Then, analytes were thermally desorbed and determined by gas chromatography-flame ionization detection (GC-FID) ${ }^{63}$. The proposed fiber showed a high durability and better performance than fibers based exclusively on activated carbon or zeolite. ${ }^{63}$ Other new SPME fiber coated with zeolite and $\mathrm{SiC}$ was presented for the preconcentration of benzene, toluene, ethylbenzene and xylenes (BTEX) from water and soil samples. ${ }^{64}$ During the extraction, the fiber was disposed in the HS of stirred water samples or sonicated soil samples. Then, the fiber was immediately inserted in the hot injection port of a GC-FID system for thermal desorption and ensuing analysis. Different fiber compositions (i.e., SiC/zeolite weight ratios) were evaluated. Results showed that coating made of $20 \% \mathrm{SiC}$ and $80 \%$ zeolite possessed the maximum ability for BTEX extraction due to a synergic combination of the adsorption capacity of zeolite and porosity given by SiC. ${ }^{64}$ Finally, a recent publication reported a comparative study of two different zeolite-based coatings 
(i.e., LTA and ZSM-5) in a new method whereby SPME was directly coupled to low temperature plasma mass spectrometry to determine organophosphate neurotoxins in water and urine samples. ${ }^{35}$ The SPME fibers consisted of a stainless steel needle coated with LTA or ZSM-5 zeolites, respectively. After the SPME in DI mode, the extraction unit was directly inserted into a low temperature plasma ionization chamber and served as ionization electrode (i.e., ionization source). The effect of a pre-conditioning step of the SPME fibers with different cations (i.e., $\mathrm{Na}^{+}$and $\mathrm{Cu}^{2+}$ ) was investigated and results showed that the presence of $\mathrm{Cu}^{2+}$ ions improved extraction yields probably due to strong $\mathrm{Cu}^{2+}$-phosphonate interactions. ${ }^{35}$ Finally, LTA zeolite showed better extraction performance due to higher density of cation-exchange sites compared to ZSM-5 and, therefore, more sites for the coordination and preconcentration of organophosphate analytes. ${ }^{35}$

All the SPME methods included in this section carried out the thermal desorption or direct determination of analytes after extraction, thereby avoiding time-consuming elution steps and reducing solvents consumption. On the contrary, as major inconvenients it could be mentioned the well-known fibers fragility and pre-conditioning steps.

\subsection{Micro-solid-phase extraction}

In micro-solid-phase extraction ( $\mu$-SPE), a small bag of porous membrane is filled with the sorbent and directly submerged into sample solution. ${ }^{71}$ Lee et al. ${ }^{37}$ proposed Linde Type L (LTL) zeolite as new sorbent for the $\mu$-SPE of ochratoxin A from coffee and cereal samples. Solid samples were previously mixed with a $\mathrm{NaHCO}_{3}$ solution, shaken and filtrated. Then, the $\mu$ - 
SPE device (i.e., zeolite packed inside a polypropylene membrane) was placed in stirred sample filtrates. After extraction, the device was retrieved, washed, dried and deposited in a small vial for analyte desorption with methanol. Finally, methanol phase was analyzed by LC-FD. LTL zeolites with different morphologies (i.e., nanosized, rods, cylinders and needles) were evaluated obtaining the best extraction yield for LTL zeolite in the form of cylinders. Authors associated these results with the existence of a higher number of accessible channels with longer lengths where the analyte could enter deeper and be trapped more effectively. ${ }^{37}$ Moreover, cylinders of LTL zeolite showed equal or greater extraction efficiency than molecularly imprinted polymers and commonly used $\mathrm{C}_{8}, \mathrm{C}_{18}$ and $\mathrm{C}_{30}$ sorbents, ${ }^{37}$ with the undoubted advantage of being a low cost and widely available material.

\subsection{Thin-film microextraction}

In thin-film microextraction (TFME), a sheet of flat film with a high surface area-to-volume ratio is used as the extraction phase. ${ }^{70}$ Goda et al..$^{36}$ proposed a novel TFME device based on ZSM-5 zeolite and Tenax TA porous polymer in order to preconcentrate acetone, hexane, cyclohexane, dichloromethane, diethyl ether, benzene, toluene, benzaldehyde, 1-pentanol and 1-octanol from water. Zeolite and Tenax TA were sequentially deposited on an aluminium support by dip-coating. The adsorption device was employed in both HS and DI extraction modes. After extraction, analytes were thermally desorbed for final determination by gas chromatography-mass spectrometry (GC-MS). Comparing the extraction performance of ZSM-5/Tenax TA and Tenax TA coatings allowed concluding that only some analytes (i.e., hexane, cyclohexane, 
dichloromethane, benzene and toluene) were better extracted with the hybrid material. Therefore, the proposed zeolite-based sorbent showed certain selectivity within tested analytes. Finally, authors pointed out the presence of unexpected peaks in the GC-MS chromatogram. These peaks were assigned to hydrocarbons and benzene derivatives coming from the thermal degradation of adsorbed compounds due to the well-known catalytic activity of ZSM-5 zeolite. ${ }^{36}$ Authors did not discuss the selection of ZMS-5 as sorbent, although the use of an alternative zeolite could have avoided degradation problems and improved analytical performance.

\subsection{Polymer monolith microextraction}

Polymer monolith microextraction (PMME) was introduced as an alternative to SPME in order to improve extraction process using high surface area polymer monoliths inside capillary columns. ${ }^{65}$ For the first time, Wang et al. ${ }^{65}$ presented the modification of a poly(methacrylic acid-ethylene dimethacrylate) column with synthetic zeolite for the extraction of seven colorants from red lipsticks. Lipsticks were dissolved in dimethyl sulfoxide and filtered before PMME. Then, sample solution was passed through the modified polymer monolithic column and eluted with an ammonia solution/methanol mixture for subsequent analysis by liquid chromatography-multiple wavelength detection. ${ }^{65}$ Zeolite modified polymer monolith was characterized by different techniques (e.g., scanning electron microscopy and thermogravimetry) showing high porous structure and thermal stability. ${ }^{65}$ In addition, a comparative study about the preconcentration ability of modified and unmodified polymer was 
conducted revealing a remarkable enhancement of analytical signal after the extraction with the proposed modified material. ${ }^{65}$

\subsection{Dispersive micro-solid-phase extraction}

Dispersive micro-solid-phase extraction (D- $\mu$-SPE) is based on the same general procedure above described for DSPE, but employing lower amounts of

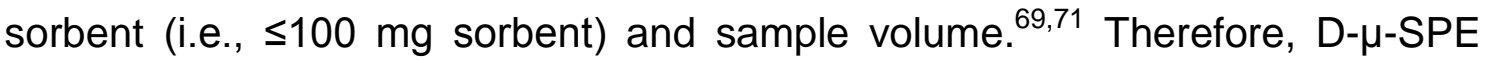
has been reported as the miniaturized mode of DSPE. A lanthanum(III) modified clinoptilolite was employed for the D- $\mu$-SPE of hemoglobin from blood samples. $^{25}$ To modify clinoptilolite, the zeolite was merely mixed with a $\mathrm{La}\left(\mathrm{NO}_{3}\right)_{3}$ solution at $100{ }^{\circ} \mathrm{C}$ for $2.5 \mathrm{~h}$. Before extraction, blood samples were diluted and erythrocytes were broken to release hemoglobin. Then, lanthanum(III) modified clinoptilolite was mixed with sample solution and, after extraction and centrifugation, the supernatant was retrieved and a $\mathrm{Na}_{3} \mathrm{PO}_{4}$ solution was added to desorb the analyte from the lanthanum(III) modified clinoptilolite. The final acceptor phase (i.e., $\mathrm{Na}_{3} \mathrm{PO}_{4}$ solution) was analyzed by sodium dodecyl sulfate-polyacrylamide gel electrophoresis. Lanthanum(III) possesses high affinity to proteins due to its ability to coordinate with oxygen, aliphatic nitrogen and phosphor ligands. ${ }^{25}$ In addition, no adsorption was observed with pure clinoptilolite showing that the affinity of lanthanum(III) with hemoglobin was the responsible force of the extraction process. Therefore, in this work zeolite was basically employed as solid support considering its easy and reproducible modification with lanthanum(III).

Bergé-Lefranc et al. ${ }^{66}$ employed mordenite for the D- $\mu$-SPE of creatinine from physiological solutions. Authors had previously studied the adsorption of 
creatinine onto mordenite, showing a good extraction performance under physiological conditions. ${ }^{23}$ For D- $\mu$-SPE, sample and sorbent were mixed until equilibrium conditions and then, phases were separated by centrifugation. During initial studies, creatinine was determined in the supernatant phase using liquid chromatography-diode array detection or a spectrophotometric method based on the Jaffé reaction. ${ }^{66}$ However, diffuse reflectance ultraviolet (DR-UV) spectroscopy measurements were performed directly on the solid phase for the final analytical quantification of the adsorbed creatinine. ${ }^{66}$ Thus, the combination of zeolite-based D- $\mu$-SPE with DR-UV is an interesting and promising alternative to those classical procedures that include a desorption step followed by a time-consuming chromatographic technique. However, the advantages of combining zeolite-based D- $\mu$-SPE with DR-UV were partially restricted in the proposed method since $12 \mathrm{~h}$ of extraction time were necessary to carried out extractions under equilibrium conditions.

In a preliminary publication, Costa et al. ${ }^{72}$ compared the physicochemical properties and extraction performance of different zeolites, namely: BEA, USY and ZSM-5, using polycyclic aromatic hydrocarbons (PAHs) as target analytes. During such studies, BEA showed the greatest efficiencies and, considering the lager external surface area, authors suggested that the adsorption of PAHs

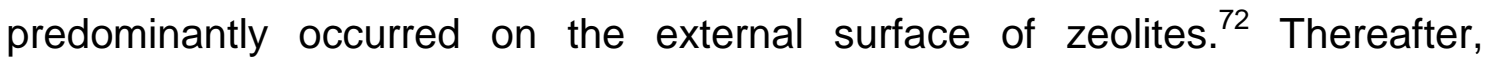
authors applied these results in two subsequent publications in which BEA was employed for PAHs determination in water samples using liquid chromatography-ultraviolet/fluorescence detection (LC-UV/FD) ${ }^{55}$ or laserexcited time-resolved Shpol'skii spectroscopy ${ }^{56}$, respectively. Briefly, BEA was added to water samples and the mixture was shaken. After centrifugation, the 
supernatant was removed and methanol/water was added for analytes desorption. ${ }^{55,56}$ Lower LODs were obtained with LC-UV/FD for the fifteen PAHs studied. Nevertheless, the method including Shpol'skii spectroscopy also met regulation requirements (i.e., LODs lower than maximum concentration levels stipulated by the Environmental Protection Agency) and, at the same time, timeconsuming chromatographic separation was avoided, thus reducing analysis time and the consumption of organic solvents.

Recently, a novel method based on vortex-assisted D- $\mu$-SPE using CTA modified NaY zeolite as sorbent was proposed by Salisaeng et al. ${ }^{48}$ to determine carbamate pesticides in fruit, vegetables and water samples. Food samples were previously extracted with an acetic acid/methanol mixture. The extractant phase was evaporated to dryness and the final residue was reconstituted with water. For D- $\mu$-SPE, CTA modified NaY zeolite was added to aqueous solution and vortex-mixed. After that, the mixture was filtered and carbamate pesticides adsorbed on the solid sorbent were eluted with methanol for subsequent determination by liquid chromatography-photodiode array detection. ${ }^{48}$ The zeolite-based sorbent used in this work had been previously employed in two above mentioned publications of the same research group. ${ }^{12,13}$ Nevertheless, D- $\mu$-SPE technique introduced remarkable advantages as shorter extraction times, less consumption of sorbent and an easier to handle procedure than SPE. 


\subsection{Magnetic solid-phase extraction}

Recently, magnetic solid-phase extraction (MSPE) has received great interest since it facilitates sorbent manipulation. ${ }^{71}$ In MSPE, the magnetic sorbent is dispersed into the aqueous phase, normally by vortex agitation ${ }^{16}$, ultrasound energy $^{17}$ or manual agitation ${ }^{18}$. After extraction, the sorbent is easily separated from the sample solution by applying an external magnetic field (e.g., with a Nd magnet). Therefore, time-consuming filtration or centrifugation steps for phase separation are avoided. Next, target analytes can be desorbed using a proper eluent solvent or temperature for further determination. ${ }^{71}$

Clinoptilolite/ $\mathrm{Fe}_{3} \mathrm{O}_{4}$ composite was recently proposed as a new sorbent for MSPE. ${ }^{16}$ In this work, phthalates were determined at trace levels in aqueous samples by GC-FID after extraction with natural clinoptilolite loaded on $\mathrm{Fe}_{3} \mathrm{O}_{4}$ nanoparticles. $^{16}$ Magnetic nanoparticles were synthesized by $\mathrm{Fe}$ electrooxidation in a tetramethylammonium chloride (TMA-Cl) solution. Then, the composite was obtained by simply mixing the zeolite with $\mathrm{Fe}_{3} \mathrm{O}_{4}$ nanoparticles in a thermostatic bath at $90{ }^{\circ} \mathrm{C}$. BET surface area, pore size and pore volume were evaluated in pure clinoptilolite and clinoptilolite $/ \mathrm{Fe}_{3} \mathrm{O}_{4}$ composite. Results revealed an increase in surface area and pore volume, but a decrease in average pore diameter in the presence of $\mathrm{Fe}_{3} \mathrm{O}_{4}$. Considering these results, authors concluded that magnetic nanoparticles were disposed on the zeolite surface forming secondary pores. ${ }^{16}$ Finally, the comparison of the proposed method (i.e., dynamic linear range, LOD, repeatability) with others methods including MSPE with different sorbent materials (e.g., $\mathrm{C}_{18} / \mathrm{Fe}_{3} \mathrm{O}_{4}$ ) showed comparable or better results. ${ }^{16}$ 
Other publication presented the preconcentration of phenolic antioxidants with magnetic ZSM-5 zeolite derived with carboxylatocalix[4]arenes $(\mathrm{CC}[4] \mathrm{A}){ }^{17}$ The magnetic zeolite was synthesized from $\mathrm{SiO}_{2}$ gel, $\mathrm{Fe}\left(\mathrm{NO}_{3}\right)_{3}$ and $\mathrm{NaAlO}_{2}$ solutions. Afterwards, it was amine functionalized and finally derived with CC[4]A. MSPE was applied to preconcentrate phenolic antioxidants from juice and milk powder samples prior to LC-UV. Authors demonstrated the more efficient preconcentration capacity of magnetic ZSM-5 zeolite derived with CC[4]A compared to magnetic ZSM-5 without derivatization. In addition, LODs were generally lower than those obtained in previous publications using different preconcentration methods (e.g., cloud point extraction, liquid-liquid extraction). ${ }^{17}$

Finally, our research group proposed a new composite based on ZSM-5 zeolite decorated with iron oxide magnetic nanoparticles as a valuable sorbent for MSPE. BTEX were proposed as model analytes and were determined in water samples by GC-MS. The magnetic composite was prepared by precipitation of $\mathrm{Fe}_{2} \mathrm{O}_{3}$ nanoparticles onto ZSM-5 zeolite. Nitrogen adsorption isotherms revealed a decrease in BET surface area and micropore volume due to the presence of magnetic nanoparticles. The proposed sorbent could be reused in at least twelve consecutive extractions. ${ }^{18}$ Finally, good extraction efficiencies were obtained for benzene, toluene and ethylbenzene. However, no preconcentration was obtained for o-xylene isomer probably due to a sterically hindered extraction. ${ }^{18}$ 


\subsection{Passive sampling}

Besides SPE and miniaturized SPE techniques, zeolites have also been proposed as sorbents in passive sampling devices. ${ }^{38,39,67}$ These devices are used for continuous monitoring of pollutants in environmental matrices, giving interesting information about long-term exposure and time-weighted average concentrations. ${ }^{67}$ In recent years, the popularity of passive sampling has increased since it combines sample collection, purification and concentration into a single step. In addition, passive sampling eliminates power supply, being cheaper and more environmentally friendly than active sampling ${ }^{67}$ Du et al. ${ }^{67}$ employed a hydrophobic silica zeolite as sorbent to monitor indoor exposure to benzene, toluene and xylenes (BTX) by passive diffuse sampling. BTX determination was performed by GC-MS after thermal desorption. The proposed device was validated under real environmental conditions giving good results at lower cost than other passive samplers ${ }^{67}$ Other publication reported the use of $13 \mathrm{X}(\mathrm{NaX})$ zeolite in heated passive HS extraction of oxygenated solvents (ignitable liquids in incendiary fires) from fire debris samples. ${ }^{39}$ The high hydrophilic character, pore diameter and available surface area of zeolite made it suitable for the extraction of small polar molecules such as acetone, methanol, ethanol or isopropanol. After extraction, target molecules were desorbed with methyl ethyl ketone and determined by GC-MS. ${ }^{39}$ The proposed passive sampler improved the recovery of oxygenated solvents under study in comparison to the commonly used activated carbon based samplers. ${ }^{39}$ The same research group employed $13 X$ zeolite in combination with activated charcoal strips for testing simultaneously oxygenated solvents and pretroleumbased compounds. ${ }^{38}$ Results confirmed initial hypothesis about the preference 
of oxygenated solvents to be adsorbed into zeolite whereas charcoal preferably recovered pretroleum products. 


\section{Extraction of metals}

For the determination of metals in different real samples (i.e. environmental, food and biological samples) by atomic emission and absorption spectrometry detection techniques, solid-phase extraction and microextraction techniques are commonly used as sample pretreatment techniques to remove complex matrices, preconcentrate analytes and make the samples suitable for subsequent sample introduction and measurements. ${ }^{73}$ Different sorbents such as metal-organic frameworks ${ }^{74}$, ion-imprinted polymers ${ }^{75}$, magnetic graphene oxides $^{76}$, carbon nanotubes ${ }^{77}$, among others, have been employed for metal extraction. However, zeolites are considered an attractive alternative to preconcentrate metals from different matrices prior to instrumental analysis, due to their properties described in the Introduction, highlighting its cation-exchange feature. This Section reviews the use of zeolites and zeolite-based materials in (micro)extraction techniques and their different modalities for metals determination. The analytical methods described in this section have been summarized in Table 3. 
Table 3. Extraction of metals using zeolites and zeolite-based materials as sorbents.

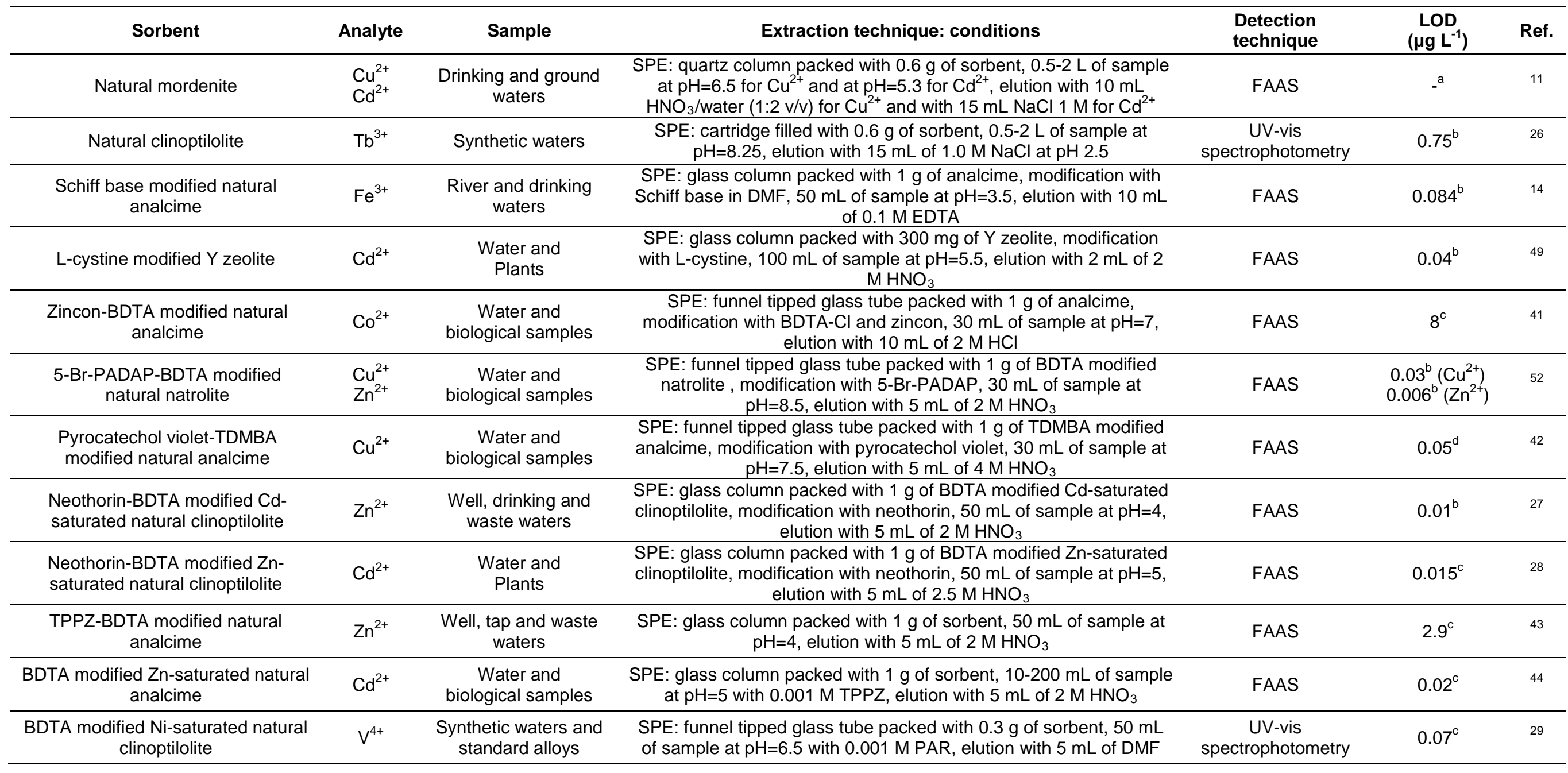




\begin{tabular}{|c|c|c|c|c|c|c|}
\hline $\begin{array}{l}\text { Zincon-TDMBA modified natural } \\
\text { analcime }\end{array}$ & $\mathrm{Pd}^{2+}$ & $\begin{array}{l}\text { Spring, river and well } \\
\text { waters }\end{array}$ & $\begin{array}{c}\text { SPE: glass column packed with } 1 \mathrm{~g} \text { of analcime, modification with } \\
\text { TDMBA }-\mathrm{Cl} \text { and zincon, } 30 \mathrm{~mL} \text { of sample at } \mathrm{pH}=3 \text {, elution with } 5 \mathrm{~mL} \\
\text { DMSO }\end{array}$ & TDS & $0.25^{\mathrm{e}}$ & 45 \\
\hline $\begin{array}{l}\text { Zincon-BDTA modified Cd-saturated } \\
\text { natural clinoptilolite }\end{array}$ & $\mathrm{Ni}^{2+}$ & Plants & $\begin{array}{l}\text { SPE: glass column packed with } 1 \mathrm{~g} \text { of BDTA modified Cd-saturated } \\
\text { clinoptilolite, modification with zincon, aliquot of sample at } \mathrm{pH}=8.5 \text {, } \\
\text { elution with } 5 \mathrm{~mL} \text { DMF }\end{array}$ & FDS-HPSAM & $\begin{array}{l}0.7^{\mathrm{c}}\left(\mathrm{Ni}^{2+}\right) \\
0.5^{\mathrm{c}}\left(\mathrm{Cu}^{2+}\right)\end{array}$ & 30 \\
\hline $\begin{array}{l}\text { Nitroso-S-BDTA modified Cd- } \\
\text { saturated natural clinoptilolite }\end{array}$ & $\begin{array}{l}\mathrm{Cu}^{2+} \\
\mathrm{Hg}^{2+}\end{array}$ & $\begin{array}{l}\text { Plant and biological } \\
\text { samples }\end{array}$ & $\begin{array}{l}\text { SPE: glass column packed with } 1 \mathrm{~g} \text { of BDTA modified Cd-saturated } \\
\text { clinoptilolite, modification with Nitroso-S, } 50 \mathrm{~mL} \text { of sample at } \\
\mathrm{pH}=8.5 \text {, elution with } 5 \mathrm{~mL} \text { DMF }\end{array}$ & FDS-HPSAM & $\begin{array}{l}0.5^{\mathrm{C}}\left(\mathrm{Cu}^{2+}\right) \\
0.1^{\mathrm{c}}\left(\mathrm{Hg}^{2+}\right)\end{array}$ & 31 \\
\hline $\begin{array}{l}\text { Nitroso-S-BDTA modified Cd- } \\
\text { saturated natural clinoptilolite }\end{array}$ & $\begin{array}{l}\mathrm{Cd}^{2+} \\
\mathrm{Hg}^{2+}\end{array}$ & $\begin{array}{l}\text { Plant and biological } \\
\text { samples }\end{array}$ & $\begin{array}{l}\text { SPE: glass column packed with } 1 \mathrm{~g} \text { of BDTA modified Cd-saturated } \\
\text { clinoptilolite, modification with Nitroso-S, } 50 \mathrm{~mL} \text { of sample at } \\
\mathrm{pH}=8.5 \text {, elution with } 5 \mathrm{~mL} \text { of DMF }\end{array}$ & FDS-HPSAM & $\begin{array}{l}0.8^{\mathrm{C}}\left(\mathrm{Cd}^{2+}\right) \\
0.1^{\mathrm{c}}\left(\mathrm{Hg}^{2+}\right)\end{array}$ & 32 \\
\hline $\begin{array}{l}\text { 5-Br-PADAP-BDTA modified natural } \\
\text { analcime }\end{array}$ & $\mathrm{Cd}^{2+}$ & $\begin{array}{l}\text { Standard alloys, } \\
\text { natural water and } \\
\text { biological samples }\end{array}$ & $\begin{array}{c}\text { SPE: funnel tipped glass tube packed with } 1 \mathrm{~g} \text { of BDTA modified } \\
\text { analcime, modification with } 5-\mathrm{Br}-\mathrm{PADAP}, 5 \mathrm{~mL} \text { of sample at } \mathrm{pH}=9 \text {, } \\
\text { elution with } 5 \mathrm{~mL} \text { of } 2 \mathrm{M} \mathrm{HNO}_{3}\end{array}$ & ASDPV & $0.05^{\mathrm{c}}$ & 15 \\
\hline $\begin{array}{l}\text { 5-Br-PADAP-BDTA modified natural } \\
\text { natrolite and 5-Br-PADAP-BDTA } \\
\text { modified natural analcime } \\
\end{array}$ & $\begin{array}{l}\mathrm{Pb}^{2+} \\
\mathrm{Cd}^{2+}\end{array}$ & Aqueous solutions & $\begin{array}{c}\text { SPE: funnel tipped glass tube packed with } 1 \mathrm{~g} \text { of BDTA modified } \\
\text { natrolite or analcime, modification with } 5-\mathrm{Br}-\mathrm{PADAP}, 0.7-1 \mathrm{~L} \text { of } \\
\text { sample, elution with } 5 \mathrm{~mL} \text { of } 2 \mathrm{M} \mathrm{HNO}_{3}\end{array}$ & ASDPV & $-{ }^{a}$ & 46 \\
\hline $\begin{array}{l}\text { PAN-HDTMA modified natural } \\
\text { clinoptilolite }\end{array}$ & $\mathrm{Zr}^{4+}$ & Tap and river waters & $\begin{array}{l}\text { SPE: funnel tipped glass tube packed with } 1 \mathrm{~g} \text { of HDTMA modified } \\
\text { clinoptilolite, modification with PAN, } 30 \mathrm{~mL} \text { of sample at } \mathrm{pH}=4 \text {, } \\
\text { elution with } 5 \mathrm{~mL} \text { of } 2 \mathrm{M} \mathrm{HCl}\end{array}$ & ICP AES & $0.1^{\mathrm{b}}$ & 33 \\
\hline $\begin{array}{l}\text { APDC modified NaA zeolite } \\
\text { APDC modified NaX zeolite }\end{array}$ & $\mathrm{Cu}^{2+}$ & $\begin{array}{l}\text { Tap, ozonized and } \\
\text { river waters }\end{array}$ & $\begin{array}{l}\text { SPE: PTFE column packed with } 20 \mathrm{mg} \text { of } \mathrm{NaA} \text { or } \mathrm{NaX} \text { zeolite, on- } \\
\text { line modification with APDC, } 4 \mathrm{~mL} \text { of sample at } \mathrm{pH}=1 \text { for } \mathrm{NaA} \text { and } \\
\mathrm{pH}=2 \text { for } \mathrm{NaX} \text {, on-line elution with } 300 \mu \mathrm{L} \text { of } \mathrm{MIBK}\end{array}$ & FI-FAAS & $\begin{array}{l}0.1^{\mathrm{b}}(\mathrm{NaA}) \\
0.4^{\mathrm{b}}(\mathrm{NaX})\end{array}$ & 40 \\
\hline APDC modified NaY zeolite & $\mathrm{Pb}^{2+}$ & $\begin{array}{l}\text { Homemade alcoholic } \\
\text { drinks }\end{array}$ & $\begin{array}{c}\text { SPE: PTFE column packed with } 20 \mathrm{mg} \text { of } \mathrm{NaY} \text { zeolite, on-line } \\
\text { modification with APDC, } 6 \mathrm{~mL} \text { of sample at } \mathrm{pH}=2.5 \text {, on-line elution } \\
\text { with } 100 \mu \mathrm{L} \text { of } \mathrm{MIBK}\end{array}$ & FI-FAAS & $1.4-3.5^{b}$ & 50 \\
\hline $\begin{array}{l}\text { APDC modified NaA zeolite } \\
\text { APDC modified NaY zeolite } \\
\text { APDC modified CaA zeolite } \\
\text { APDC modified CaY zeolite }\end{array}$ & $\begin{array}{l}\mathrm{Pb}^{2+} \\
\mathrm{Cd}^{2+} \\
\mathrm{Ni}^{2+} \\
\mathrm{Co}^{2+}\end{array}$ & Drinking waters & $\begin{array}{c}\text { SPE: PTFE column packed with } 20 \mathrm{mg} \text { of } \mathrm{NaA}, \mathrm{NaY}, \mathrm{CaA} \text { or } \mathrm{CaY} \\
\text { zeolite, on-line modification with } \mathrm{APDC}, 6 \mathrm{~mL} \text { of sample, on-line } \\
\text { elution with } 4 \mu \mathrm{L} \mathrm{min} \mathrm{min}^{-1} \mathrm{MIBK}\end{array}$ & FI-FAAS & $\begin{array}{l}0.3-1.9^{\mathrm{C}}\left(\mathrm{Pb}^{2+}\right) \\
2.3-5.6^{\mathrm{C}}\left(\mathrm{Cd}^{2+}\right) \\
0.4-0.7^{\mathrm{C}}\left(\mathrm{Ni}^{2+}\right) \\
0.8-2.1^{\mathrm{C}}\left(\mathrm{Co}^{2+}\right)\end{array}$ & 51 \\
\hline $\begin{array}{l}2,6-D A P-P A \\
\text { hybrid }\end{array}$ & $\begin{array}{l}\mathrm{Pb}^{2+} \\
\mathrm{Ni}^{2+} \\
\mathrm{Cu}^{2+} \\
\mathrm{Cd}^{2+}\end{array}$ & $\begin{array}{l}\text { Water and } \\
\text { Vegetables }\end{array}$ & $\begin{array}{l}\text { SPE: glass column packed with } 50 \mathrm{mg} \text { of sorbent, } 500 \mathrm{~mL} \text { of water } \\
\text { sample and } 25 \mathrm{~mL} \text { of solution of vegetable sample at } \mathrm{pH}=5.5 \\
\text { elution with } 10 \mathrm{~mL} 1 \mathrm{M} \mathrm{HNO}_{3}\end{array}$ & FAAS & $\begin{array}{l}35^{\mathrm{b}}\left(\mathrm{Pb}^{2+}\right) \\
76^{\mathrm{b}}\left(\mathrm{Ni}^{2+}\right) \\
83^{\mathrm{b}}\left(\mathrm{Cu}^{2+}\right) \\
79^{\mathrm{b}}\left(\mathrm{Cd}^{2+}\right)\end{array}$ & 57 \\
\hline A-4 zeolite & $\mathrm{Cd}^{2+}$ & $\begin{array}{l}\text { Lake and river waters } \\
\text { and wastewater }\end{array}$ & $\begin{array}{c}\text { D- } \mu \text {-SPE: } 100 \mathrm{mg} \text { of sorbent, } 100 \mathrm{~mL} \text { of sample at } \mathrm{pH}=6 \text {, extraction } \\
\text { for } 20 \mathrm{~min} \text {, solid phase was separated from the sample by a } \\
\text { membrane filter, dissolved with } 2 \mathrm{~mL} \text { of } 2 \mathrm{M} \mathrm{HNO}_{3}\end{array}$ & GFAAS & $0.002^{b}$ & \\
\hline
\end{tabular}




\begin{tabular}{|c|c|c|c|c|c|c|}
\hline G-CL hybrid & $\mathrm{Pb}^{2+}$ & $\begin{array}{l}\text { Water and } \\
\text { human serum }\end{array}$ & $\begin{array}{c}\text { D- } \mu \text {-SPE: } 5 \mathrm{mg} \text { of sorbent, } 2 \mathrm{~mL} \text { of water sample or serum sample } \\
\text { diluted with deionized water }(1: 1, \mathrm{v} / \mathrm{v}) \text { at } \mathrm{pH}=5 \text {, extraction in an } \\
\text { ultrasonic bath for } 60 \mathrm{~s} \text {, elution with } 100 \mu \mathrm{L} \text { of } 0.5 \mathrm{M} \mathrm{HNO}_{3}\end{array}$ & ETAAS & $\begin{array}{l}0.07^{\mathrm{b}}\left(\mathrm{Pb}^{2+}\right) \\
0.004^{\mathrm{b}}\left(\mathrm{Cd}^{2+}\right)\end{array}$ & 34 \\
\hline $\begin{array}{l}\text { DHPDT modified magnetic NaY } \\
\text { zeolite }\end{array}$ & $\begin{array}{l}\mathrm{Cu}^{2+} \\
\mathrm{Cd}^{2+}\end{array}$ & Water and soil & $\begin{array}{c}\text { MSPE: } 40 \mathrm{mg} \text { of sorbent, } 10 \mathrm{~mL} \text { of sample at } \mathrm{pH}=6 \text {, extraction with } \\
\text { overhead strirrer for } 9 \text { min, upper aqueous phase was used for } \\
\text { determination }\end{array}$ & FI-FAAS & $-^{a}$ & 19 \\
\hline $\begin{array}{l}\text { DDTC-HDTMA modified Zn- } \\
\text { saturated ZSM-5/Fe }{ }_{2} \mathrm{O}_{3}\end{array}$ & $\begin{array}{l}\mathrm{Cd}^{2+} \\
\mathrm{Hg}^{2+} \\
\mathrm{Pb}^{2+}\end{array}$ & Urine & $\begin{array}{l}\text { MSPE: } 50 \mathrm{mg} \text { of sorbent, } 20 \mathrm{~mL} \text { of sample at } \mathrm{pH}=4 \text {, manual } \\
\text { agitation for } 3 \mathrm{~min} \text {, elution with } 432 \mu \mathrm{L} \text { of } 11.8 \mathrm{MNO}_{3} \text { for } 2 \mathrm{~min}\end{array}$ & ICP OES & $\begin{array}{l}0.15-0.20^{\mathrm{b}}\left(\mathrm{Cd}^{2+}\right) \\
0.42-0.73^{\mathrm{b}}\left(\mathrm{Hg}^{2+}\right) \\
0.23-0.79^{\mathrm{b}}\left(\mathrm{Pb}^{2+}\right)\end{array}$ & 20 \\
\hline
\end{tabular}

LOD, limit of detection; SPE, solid-phase extraction; FAAS, flame atomic absorption spectrometry; UV-vis, ultraviolet-visible; Schiff base, 5-((4-nitrophenylazo)-N-(2',4'dimethoxyphenyl))salicylaldimine; DMF, dimethylformamide; EDTA, ethylenediaminetetraacetic acid; zincon, 2-[1-(2-hydroxy-5-sulforphenyl)-3-phenyl-5-formazano]-benzoic acid monosodium salt; BDTA, benzyldimethyltetradecylammonium; BDTA-Cl, benzyldimethyltetradecylammonium chloride; 5-Br-PADAP, 2-(5-bromo-2-pyridylazo)-5-diethylaminophenol; TDMBA, tetradecyldimethylbenzylammonium; TDMBA-Cl, tetradecyldimethylbenzylammonium chloride; neothorin, 3-(2-arsenophenylazo)-4,5-dihydroxy-2,7-naphthalene disulfonic acid; TPPZ, 2,3,5,6tetra(2-pyridyl)pyrazine; PAR, 4-(2-pyridylazo)resorcinol; DMSO, dimethylsulfoxide; TDS, third-order derivative spectrophotometry; FDS-HPSAM, first-order derivative spectrophotometry-H-point standard addition method; Nitroso-S, 2-nitroso-1-naphthol-4-sulfonic acid; ASDPV, anodic stripping differential pulse voltammetry; PAN, 1-(2-pyridylazo)-2-naphtol; HDTMA, hexadecyltrimethylammonium; ICP AES, inductively coupled plasma atomic emission spectrometry; APDC, ammonium pyrrolidine dithiocarbamate; PTFE, polytetrafluoroethylene; MIBK, methyl isobutyl ketone; FI-FAAS, flow injection flame atomic absorption spectrometry; 2,6-DAP, 2,6-diacetyl pyridine; PA, 3-aminopropyl trimethoxy silane; D- $\mu$-SPE, dispersive micro-solid-phase extraction; GFAAS, graphite furnace atomic absorption spectrometry; G-CL, graphene-clinoptilolite; ETAAS, electrothermal atomic absorption spectrometry; DHPDT, 2-(3,4-dihydroxyphenyl)-1,3-dithiane; MSPE, magnetic solid-phase extraction; DDTC, sodium diethyldithiocarbamate trihydrate; ICP OES, inductively coupled plasma optical emission spectrometry.

a LOD not mentioned by the authors.

${ }^{b}$ Calculated using $3 s_{\text {blank }} / m$, where $s_{\text {blank }}$ is the standard deviation of blank and $m$ is a slope of the calibration curve.

LOD calculation not mentioned.

Calculated using $2 s_{\text {blank }} / m$, where $s_{\text {blank }}$ is the standard deviation of blank and $m$ is a slope of the calibration curve.

${ }^{\mathrm{e}}$ Obtained at the optimal instrumental settings (signal-to-noise ratio $=3$ ). 


\subsection{Solid-phase extraction}

A natural mordenite was used by Vasylechko et al. ${ }^{11}$ to determine $\mathrm{Cu}^{2+}$ and $\mathrm{Cd}^{2+}$ in drinking and ground waters by flame atomic absorption spectrometry (FAAS). Firstly, mordenite was thermally treated at $150{ }^{\circ} \mathrm{C}$ for 2.5 $\mathrm{h}$ to remove the humidity present in the natural zeolites, which affects significantly to their sorption capacity. For SPE, sample solutions adjusted to $\mathrm{pH}$ 6.5 and 5.3 for $\mathrm{Cu}^{2+}$ and $\mathrm{Cd}^{2+}$, respectively, were passed through a quartz column packed with the mordenite and then, analytes were eluted using $\mathrm{HNO}_{3} /$ water $(1: 2, \mathrm{v} / \mathrm{v})$ and $1 \mathrm{M} \mathrm{NaCl}$ solutions, respectively. The presence of foreign ions in the solution was studied and the results showed a high selectivity of the developed method. Under optimum conditions the extraction efficiency was $99.8 \%$ for $\mathrm{Cu}^{2+}$ and $94 \%$ for $\mathrm{Cd}^{2+}$. Finally, the results obtained with this column were compared with a commercial extraction column "Diapak IDK", obtaining a good agreement. In a later publication, the same research group determined trace amounts of $\mathrm{Tb}^{3+}$ in synthetic water samples using a natural clinoptilolite. ${ }^{26}$ In this case, clinoptilolite was also heated and stored in a desiccator before using it in SPE. Water samples, adjusted to $\mathrm{pH} 8.25$, were passed through the column containing the zeolite; then $\mathrm{Tb}^{3+}$ was eluted from the column with $1 \mathrm{M} \mathrm{NaCl}$ solution, and finally determined spectrophotometrically using the method of arsenazo III. Under optimum conditions, an enrichment factor of 130 was obtained. Finally, the method was applied to synthetic water samples obtaining recovery values ranging from 93.3 to $103.0 \%$. Both methods present the advantage that the zeolites were not modified prior to SPE procedure, just thermally activated. 
In order to increase the metal preconcentration capacity of zeolites, the modification of the zeolites by different materials (i.e., Schiff base, as 5-((4nitrophenylazo)-N-(2',4'-dimethoxyphenyl))salicylaldimine, and L-cystine), which act as chelating agents, has been reported. These compounds are immobilized on a zeolite, facilitating the metal retention on the zeolites by complex formation. Related to this, Shamspur et al. ${ }^{14}$ developed an analytical method to determine $\mathrm{Fe}^{3+}$ in river and drinking water samples by FAAS using a column loaded with natural analcime modified with a new Schiff base, since this ligand forms stable complexes with some transition metals. Firstly, analcime was sieved, washed with $4 \mathrm{M} \mathrm{HCl}$ and dried due to its natural origin, therefore, presenting different particle sizes and soluble impurities. This step could be avoided using a synthetic zeolite. Then, the Schiff base was prepared by condensation reaction between a precursor ligand with 2-methoxy-3-nitroaniline in hot ethanol. Some preliminary experiments showed that analcime by itself did not retain $\mathrm{Fe}^{3+}$, while the analcime column modified with a Schiff base showed retention capacity. The authors compared their method with other systems and the main advantages were that natural analcime was low cost, and the LOD value (i.e., $0.084 \mu \mathrm{g} \mathrm{L}^{-1}$ ) was much lower than others (i.e, $11^{78}, 3.3^{79}$ and $12^{80}$ $\mu \mathrm{g} \mathrm{L}^{-1}$ ). Rezvani et al. ${ }^{49}$ proposed $\mathrm{Y}$ zeolite modified with L-cystine as new sorbent for the SPE of $\mathrm{Cd}^{2+}$ from water and plant samples (i.e., black tea and cigarette's tobacco). Plant samples were previously dried and dissolved in concentrated $\mathrm{HNO}_{3}$ followed by heating. Then, they were passed through the column packed with L-cystine modified $\mathrm{Y}$ zeolite. After extraction, $\mathrm{Cd}^{2+}$ sorption was eluted with $2 \mathrm{M} \mathrm{HNO}_{3}$ for further determination by FAAS. The oxidized form of L-cystine is a good complexing agent due to the presence of two carboxyl 
groups, two amino groups and two sulfur atoms in its structure. On the one hand, Fourier Transform Infrared (FT-IR) spectroscopy was applied to demonstrate the adsorption of L-cystine into the zeolite and on the other hand, powder X-ray diffraction (XRD) spectroscopy indicated that L-cystine molecules were physically adsorbed into the zeolite pores without disturbing its original structure. The results of interference study showed that the proposed method was selective for $\mathrm{Cd}^{2+}$, and recoveries and relative standard deviation (RSD) demonstrated the applicability and the excellent repeatability of this method. Finally, L-cystine modified $Y$ zeolite showed equal or better results of LOD, preconcentration factor, sorbent capacity and repeatability than imprinted polymers, functionalized magnetic nanoparticles and active carbon sorbents. ${ }^{49}$

The modification of the zeolites, firstly, by cationic surfactants (i.e., benzyldimethyltetradecylammonium chloride (BDTA-Cl), tetradecyldimethylbenzylammonium chloride (TDMBA-Cl) and hexadecyltrimethylammonium bromide (HDTMA-Br)) and then, by different chelating agents has been also reported in different publications..$^{15,20,27,28,30-33,41-43,45,46,52}$ In many cases, zeolites cannot adsorb chelating agents molecules because its pore size is smaller than the dimensions of these chelating agents. Additionally, zeolites are negatively charged and, therefore, anionic groups of chelating agents will be repelled from negatively charged zeolite surface. For this reason, to increase the adsorption capacity, the zeolites are first modified with a cationic surfactant. $^{81}$ If the surfactant concentration exceeds the critical micelle concentration $(\mathrm{CMC})$, then the hydrophobic tails of the surfactant form a bilayer. Finally, the chelating agent is immobilized on cationic surfactant-coated zeolite since surfactant modified zeolite has positively charged exchange sites formed 
by the positive groups of the surfactant. An example of the modification of zeolite with surfactant and chelating agent is schematically shown in Fig. 5.

(a)

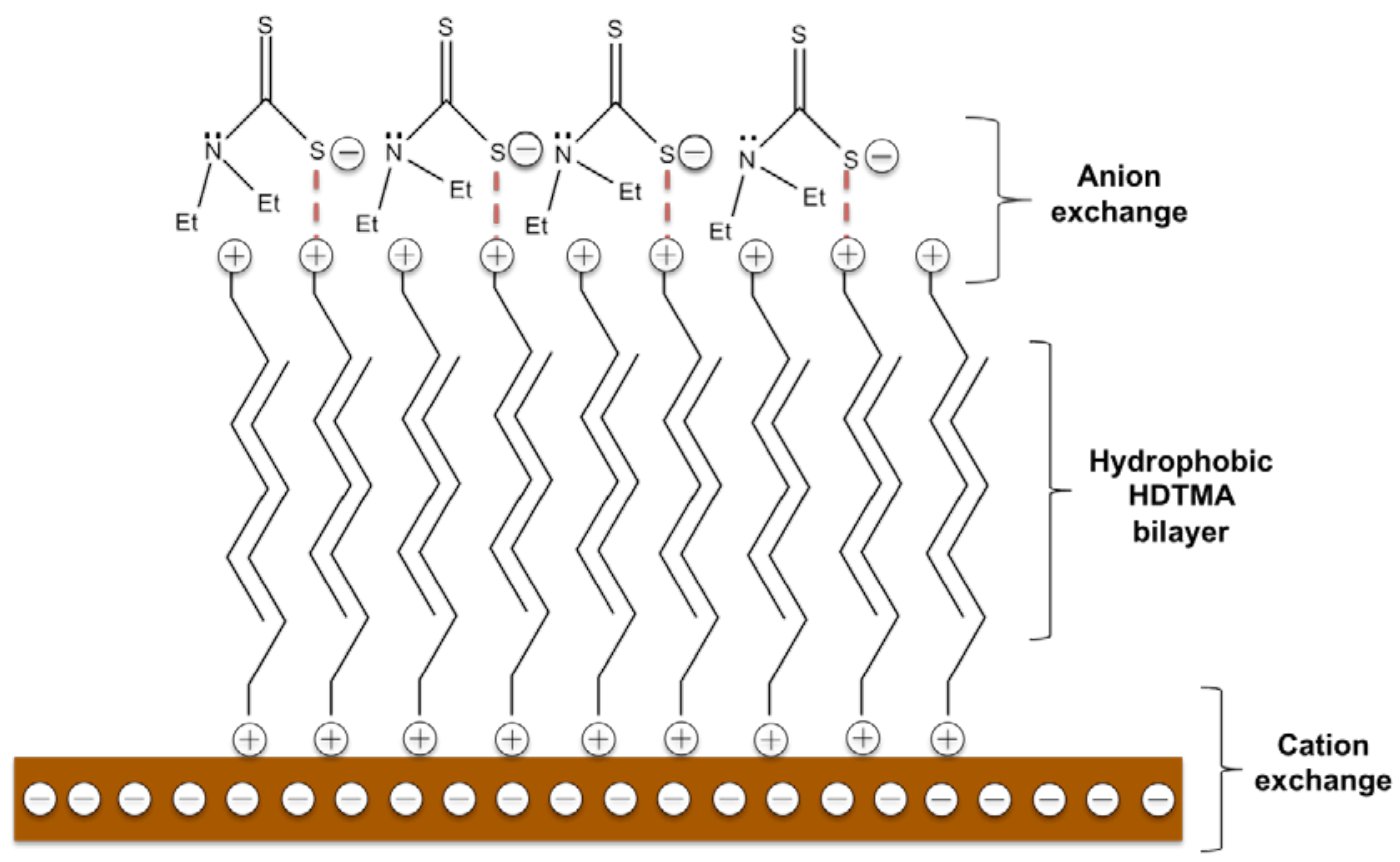

External zeolite surface

(b)

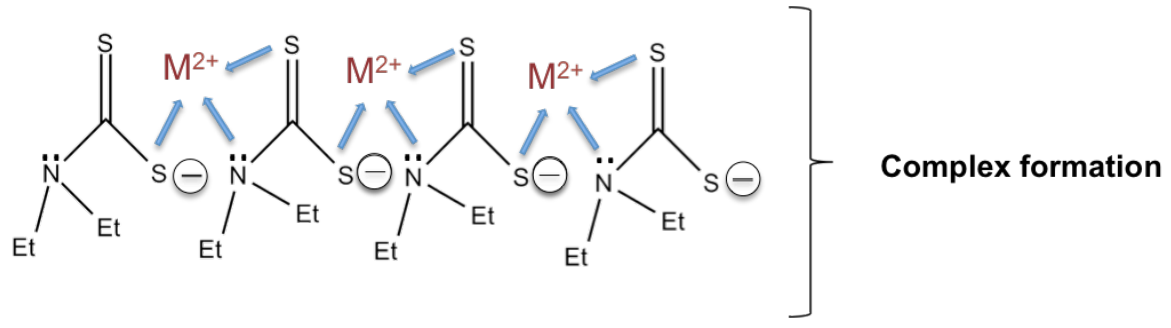

Fig. 5. Scheme of a zeolite surface modified by HDTMA-Br surfactant and DDTC chelating agent (a) adapted from Ref. ${ }^{82}$; and complex formation of DDTC with $\mathrm{M}^{2+}$ cations (b). "Reproduced from Ref. ${ }^{20}$ with permission of The Royal Society of Chemistry. Copyright (2018)". 
Taher et al. described several analytical methods to determine $\mathrm{Co}^{2+41}$, $\mathrm{Cu}^{2+42,52}, \mathrm{Zn}^{2+27,52}$ and $\mathrm{Cd}^{2+28}$ all in environmental and biological samples using columns loaded with natural zeolites modified with cationic surfactant and chelating agents. In these works, firstly, zeolites were washed with $\mathrm{HCl}$ to remove soluble impurities, sieved and washed with $\mathrm{HNO}_{3}$ to remove the cations, especially $\mathrm{Cu}$ or $\mathrm{Zn}$, coming from the natural source of the zeolites. However, these impurities could have affected the $\mathrm{Cu}$ or $\mathrm{Zn}$ determination even though $\mathrm{HNO}_{3}$ washes. Secondly, zeolites were modified with BDTA-Cl or TDMBA-Cl. It should be noted that in the first work $^{41}$, the surfactant solution was passed through the natural zeolite column, whereas in other works ${ }^{27,28,42,52}$, the natural zeolites were previously modified with the surfactant by stirring and then packed in the columns. Finally, different chelating agents, depending on which metal or metals had to be determined (i.e., 2-[1-(2-hydroxy-5-sulforphenyl)-3phenyl-5-formazano]-benzoic acid monosodium salt (zincon) ${ }^{41}$, 2-(5-bromo-2pyridylazo)-5-diethylaminophenol (5-Br-PADAP) ${ }^{52}$, pyrocatechol violet ${ }^{42}$ and 3(2-arsenophenylazo)-4,5-dihydroxy-2,7-naphthalene disulfonic acid (neothorin $)^{27,28}$ ), were used. In preliminary studies with zeolites and modified zeolites, the authors showed that raw zeolites (i.e., without surfactant and chelating agent) and BDTA or TDMBA modified zeolites (i.e., without chelating agent) were not suitable for the separation and preconcentration of metals because of the low recovery values obtained. However, zeolites modified with BDTA or TDMBA and chelating agents were selective and sensitive for separation and preconcentration of trace amount of the studied metals. In these five studies, the retained metals were desorbed from the column with $\mathrm{HNO}_{3}$ as eluent, except in the first work ${ }^{41}$ in which $\mathrm{Co}^{2+}$ was eluted with $\mathrm{HCl}$. In addition, 
interference studies showed that among the anions and cations examined, except ethylenediaminetetraacetic acid (EDTA), most of them could be tolerated up to milligram levels. Finally, it should be noted that recoveries and RSD demonstrated the applicability and the excellent repeatability of these five methods

Following the same research line, Saljooghi et al. proposed a BDTA modified natural analcime for preconcentration of trace amounts of $\mathrm{Zn}^{2+43}$ and $\mathrm{Cd}^{2+44}$ from water and biological samples. The main difference with previous methods reported by Taher et al. $^{27,28,41,42,52}$ is that the natural analcime, after purification and sieving, was mixed with $\mathrm{NH}_{4} \mathrm{NO}_{3}$ to exchange $\mathrm{Na}^{+}$by $\mathrm{NH}_{4}{ }^{+}$, obtaining the $\mathrm{NH}_{4}{ }^{+}$-form zeolite and then, it was calcined at $380{ }^{\circ} \mathrm{C}$ to obtain $\mathrm{H}^{+}$form to increase its ion-exchange capacity. In the first publication, both BDTA and TPPZ (i.e., 2,3,5,6-tetra(2-pyridyl)pyrazine) modification was carried out in batch mode. ${ }^{43}$ However, in the second publication before BDTA modification, the pores of $\mathrm{H}^{+}$-form of analcime were saturated with $\mathrm{Zn}$ to prevent the entrance of analytes into pores of zeolite, so that, adsorption of $\mathrm{Cd}^{2+}$ takes place at the outer surface. ${ }^{44}$ In addition, the TPPZ chelating agent was added to the sample instead of the sorbent. ${ }^{44}$ The influence of analcime particle size in the adsorption of $\mathrm{Cd}^{2+}$ was investigated after sieving the analcime to different size ranges (i.e., $0.315-0.180 ; 0.180-0.140 ; 0.140-0.125 ; 0.125-0.11$; and $<0.110$ $\mathrm{mm}$ ). The accuracy of both methods was evaluated by analyzing reference materials of alloys obtaining recoveries of $\mathrm{Zn}^{2+}$ and $\mathrm{Cd}^{2+}$ in good agreement with the certified values. Finally, the results obtained with the proposed methods were compared with those obtained by graphite furnace atomic absorption 
spectrometry (GFAAS), due to its better sensitivity, demonstrating the applicability of both methods.

All reported publications up to now have employed FAAS as detection technique, except the publication in which $\mathrm{Tb}^{3+}$ was determined by UV-vis spectrophotometry. ${ }^{26}$ However, other techniques such as UV-vis spectrophotometry $^{29}$, derivative spectrophotometry ${ }^{45}$, combination of first-order derivative spectrophotometry (FDS) with $\mathrm{H}$-point standard addition method $(\text { HPSAM) })^{30-32}$, anodic stripping differential pulse voltammetry (ASDPV) $)^{15,46}$ and inductively coupled plasma atomic emission spectrometry (ICP AES) ${ }^{33}$ were employed.

Taher et al. developed several analytical methods using UV-vis spectrophotometers as detection systems, characterized by their simplicity and low cost in comparison with other spectrometric detection systems that require expensive instruments (i.e., ICP AES). A BDTA modified natural clinoptilolite saturated with $\mathrm{Ni}^{2+}$ was used as a sorbent for preconcentration and determination of $\mathrm{V}^{4+}$ by UV-vis spectrophotometry in synthetic waters and standard alloys. ${ }^{29}$ The difference with the previous described methods is that the 4-(2-pyridylazo)resorcinol (PAR) as a chelating agent was added to the sample instead of to the sorbent, except report ${ }^{44}$ in which TPPZ was also added to the sample. Then, this solution was passed through the column, containing the BDTA modified Ni-saturated natural clinoptilolite, and the adsorbed complex was eluted with dimethylformamide (DMF). The accuracy of the method was evaluated and the obtained results were in agreement with certified values. Finally, the present method was compared with others methods described in literature and its LOD value (i.e., $0.07 \mu \mathrm{g} \mathrm{L}^{-1}$ ) was comparable and lower than 
those presented by other methods (i.e., $0.6^{83}, 0.2^{84} \mu \mathrm{L} \mathrm{L}^{-1}$, among others). The same research group proposed a column packed with TDMBA modified natural analcime loaded with zincon for preconcentration of $\mathrm{Pd}^{2+}$ from water samples. ${ }^{45}$ The $\mathrm{Pd}^{2+}$ complex was eluted from the column with dimethylsulfoxide (DMSO) and determined by third-derivative spectrophotometry. In this work, first TDMBA-Cl solution was passed through the column packed with natural analcime and then, TDMBA modified analcime was modified passing a zincon solution through the column. Both instrumental parameters (i.e, wavelength, scanning speed, wavelength increment over which the derivative is obtained $(\Delta \lambda)$ and response time) and reaction conditions (i.e., sample $\mathrm{pH}$, flow rate of the sample and the eluent, nature and volume of eluent) were optimized. Finally, the method was successfully applied to different water samples. Usually, most of the methods that use spectrophotometers suffer from interferences and/or high detection limits. However, by means of derivative spectrophotometry, sharper zero-order bands and a higher signal in the resolution spectra were obtained, solving classical analytical drawbacks of spectrophotometry.

Regarding spectrophotometric techniques, Taher et al. described three analytical methods to determine $\mathrm{Ni}^{2+30}, \mathrm{Cu}^{2+30,31}, \mathrm{Hg}^{2+31,32}$, and $\mathrm{Cd}^{2+32}$ from both in plants and biological samples by FDS-HPSAM. HPSAM is one of the mathematical treatment data procedures utilized for the analysis of multicomponent systems. However, in these works HPSAM could not be applied for the simultaneous determination of $X$ and $Y$ metals due to high overlap between their two spectra and the absence of two wavelengths for complexes of $\mathrm{X}$ and $\mathrm{Y}$. By FDS, spectra with better resolutions and with two 
wavelengths versus the zero-order spectra were obtained. In the three publications, BDTA modified Cd-saturated natural clinoptilolite was packed in a glass column and then, a zincon solution ${ }^{30}$ and Nitroso-S (i.e., 2-nitroso-1naphthol-4-sulfonic acid) solution ${ }^{31,32}$ were passed through the column. The adsorbed analytes on the column were eluted with DMF. In the second ${ }^{31}$ and third $^{32}$ publication, the plant samples, previously digested, were analysed by FAAS and GFAAS, respectively, to compare with the proposed method, obtaining results in good agreement. Finally, it should be noted that in a later publication $^{32}$ the column was stable up to at least 30 cycles without decreasing recovery values and the comparison with other methods showed that the time consumption of the proposed method was lower than the others.

Regarding publications in which metals were determined by electroanalytical technique as ASDPV, Afzali et al. ${ }^{15}$ developed a procedure using a column of BDTA modified natural analcime and loaded with 5-BrPADAP for $\mathrm{Cd}^{2+}$ preconcentration. The $\mathrm{Cd}^{2+}$ retained on the column was eluted with $\mathrm{HNO}_{3}$, obtaining a preconcentration factor of 140 , and finally measured by ASDPV. It should be noted that the RSD was $0.31 \%$, highlighting the excellent repeatability. Finally, this method was successfully applied for the determination of $\mathrm{Cd}^{2+}$ in standard alloys, natural water and biological samples. On the other hand, Jamshidi et al. $^{46}$, following the same research line, used BDTA modified natural analcime and BDTA modified natural natrolite loaded with the same chelating agent and eluent solvent for $\mathrm{Pb}^{2+}$ and $\mathrm{Cd}^{2+}$ determination in aqueous samples. The recoveries were higher than $99 \%$ for both zeolites and preconcentration factors were 200 and 140 for $\mathrm{Pb}^{2+}$ and $\mathrm{Cd}^{2+}$, respectively. The 
authors did not provide quality analytical parameters such as linear range, LOD, repeatability, among others, and real samples were not analysed.

Faghihian et al. ${ }^{33}$ developed the first method, to our knowledge, to preconcentrate $\mathrm{Zr}^{4+}$ in water samples employing a HDTMA modified natural clinoptilolite loaded with 1-(2-pyridylazo)-2-naphthol (PAN) as a chelating agent. $\mathrm{Zr}^{4+}$ was eluted with $\mathrm{HCl}$ and determined by ICP AES. The applicability of this method was investigated analyzing spiked tap and river water samples, obtaining recoveries higher than 95\%. The reuse study confirmed that the column could be used up to 8 times. Compared to previous methods, the LOD of the proposed method was lower than others, and its selectivity versus $\mathrm{K}^{+}$, $\mathrm{Ca}^{2+}, \mathrm{Mg}^{2+}, \mathrm{NH}^{4+}, \mathrm{Na}^{+}, \mathrm{Cl}^{-}$, and $\mathrm{CH}_{3} \mathrm{COO}^{-}$was comparable with other sorbents (i.e., silica gel, vinyl polymer resin, among others). This method employs an ICP AES, which can determine different elements simultaneously, however, just one analyte (i.e., $\mathrm{Zr}^{4+}$ ) was studied.

All reported publications up to now have employed SPE as extraction technique; however, it presents disadvantages such as the column packing and the time-consuming process of loading large volume of samples. Therefore, some modifications were proposed to the SPE technique as the reduction of sorbent amount. ${ }^{40,50,51,57}$ The amount of sorbent to prepare the column was much lower (i.e., 20 or $50 \mathrm{mg}$ ) than in the publications mentioned above (i.e., 1 g). The reduction of the amount of sorbent generated advantages such as shorter extraction times and smaller volumes of samples and eluents. Petit de Peña et al. ${ }^{40}$ developed a flow injection flame atomic absorption spectrometry (FI-FAAS) for on-line preconcentration and determination of $\mathrm{Cu}^{2+}$ using synthetic zeolites. It was the first time that synthetic zeolites were used as 
adsorptive material to determine $\mathrm{Cu}^{2+}$ traces. In this work, the determination was based on the formation of a chelate of $\mathrm{Cu}^{2+}$ with ammonium pyrrolidine dithiocarbamate (APDC). Firstly, columns were packed with $20 \mathrm{mg}$ of $\mathrm{NaA}$ and NaX zeolites (i.e., in the report are mentioned as Na-LTA and Na-FAU); secondly, sample and APDC were continuously passed through, then the chelate was eluted with methyl isobutyl ketone (MIBK), and finally $\mathrm{Cu}^{2+}$ was determined by FAAS. Comparative studies were carried out using the same amount of $\mathrm{C}_{18}$ sorbent. Interferences study showed that synthetic zeolites were more selective than $\mathrm{C}_{18}$ sorbent. In addition, comparison of analytical parameters such as LOD, RSD and preconcentration factor showed better results for synthetic zeolites than $\mathrm{C}_{18}$. The zeolite columns were used daily for 2 months with no apparent deterioration in their performance. In a later publication, the same research group used the continuous flow system for the determination of $\mathrm{Pb}^{2+}$ in homemade alcoholic drinks. ${ }^{50}$ The optimum conditions of adsorption and desorption process were similar to the previous publication. However, in this case only NaY zeolite (i.e., in the report are mentioned as NaFAU) was used. In this work, due to ethanol and $\mathrm{Cu}^{2+}$ strongly interfered in $\mathrm{Pb}^{2+}$ determination, ethanol was eliminated by rotaevaporation, and $\mathrm{Cu}^{2+}$ was removed by precipitation with rubeanic acid. Finally, it should be noted that preconcentration factors from 80 up to 140 were achieved depending on the sample nature. Nine years later, the same research group ${ }^{51}$ determined $\mathrm{Pb}^{2+}$, $\mathrm{Cd}^{2+}, \mathrm{Ni}^{2+}$ and $\mathrm{Co}^{2+}$ in water samples (i.e., drinking waters) following similar procedure than in the two previous publications. ${ }^{40,50}$ The synthetic zeolites used to pack the columns (i.e., $20 \mathrm{mg}$ of sorbent) were $\mathrm{NaA}, \mathrm{NaY}, \mathrm{CaA}$ and $\mathrm{CaY}$ zeolites (i.e., in the report are mentioned as Na-LTA, Na-FAU, Ca-LTA and Ca- 
$\mathrm{FAU}$ ). $\mathrm{CaA}$ and $\mathrm{CaY}$ were obtained by ion exchange using a $\mathrm{CaCl}_{2}$ solution starting from NaA and NaY zeolites, respectively. The columns could be used in more than 200 experiments without any loss in its sorption capacity. Under optimum conditions, preconcentration factors from 21 up to 250 were achieved, confirming a high retention of the studied metals.

Finally, it should be mentioned one publication in which Yapati et al. ${ }^{57}$ developed a column loaded with $50 \mathrm{mg}$ of a new hybrid sorbent employed to extract $\mathrm{Pb}^{2+}, \mathrm{Ni}^{2+}, \mathrm{Cu}^{2+}$ and $\mathrm{Cd}^{2+}$ from water and vegetable samples. The hybrid sorbent was synthesized by grafting 3-aminopropyl trimethoxy silane (PA) onto beta zeolite (i.e., in the report is mentioned as $\beta$-zeolite), and functionalization with 2,6-diacetyl pyridine (2,6-DAP) in a stepwise covalent process. FT-IR spectra of beta zeolite, PA-beta zeolite and 2,6-DAP-PA modified beta zeolite (before and after metal binding) established the successful grafting of the organic moiety on the surface of the beta zeolite and metal chelation with organic functional groups. Additionally, nitrogen adsorption-desorption isotherms of beta zeolite and 2,6-DAP-PA modified beta zeolite showed that the microporous structure was not disturbed even after surface modification. However, the surface area, pore size and pore volume of beta zeolite decreased after surface modification. The accuracy of the method was estimated by analyzing reference standard materials, obtaining under optimum conditions a good trueness and RSD was lower than $3.1 \%$. It should be mentioned that LODs values of this method (i.e., 35, 76, 83 and $59 \mu \mathrm{g} \mathrm{L}^{-1}$ for $\mathrm{Pb}^{2+}, \mathrm{Ni}^{2+}, \mathrm{Cu}^{2+}$ and $\mathrm{Cd}^{2+}$, respectively) are slightly higher than those review in the literature for the same purpose (Table 3). 


\subsection{Dispersive micro-solid-phase extraction}

Unlike high number of reported SPE publications using zeolites as sorbents for metal extraction, only two publications have been reported for $D-\mu-$ SPE technique. ${ }^{69,71}$ On one hand, Minamisawa et al. ${ }^{53}$ developed a method for the preconcentration and determination of $\mathrm{Cd}^{2+}$ in water samples using A-4 zeolite and GFAAS detection technique, respectively. Even though the authors considered the procedure as SPE, the work has been included in this section because the sorbent was not packed in a column but directly dispersed in the sample. In preliminary experiments several types of inorganic adsorbents (i.e., A-4 zeolite, F-9 zeolite, X-13 zeolite and alumina) were investigated, obtaining better recoveries with A-4 zeolite. Extraction procedure consisted on dispersing $100 \mathrm{mg}$ of A-4 zeolite into the sample by conventional stirring, then separation of the sorbent from the sample by a membrane filter, and finally, it was dissolved in $2 \mathrm{M} \mathrm{HNO}_{3}$. It is important to point out that the feature of this method was the direct injection of the sample solution (i.e., this solution containing $\mathrm{Cd}^{2+}$ and the dissolved A-4 zeolite) into the graphite furnace. According to this, the solubility of A-4 zeolite and the viscosity of the resulting solution were investigated using $\mathrm{HCl}$ and $\mathrm{HNO}_{3}$. The results showed that $\mathrm{HNO}_{3}$ was more effective for the dissolution of A-4 zeolite. However, the dissolution of the zeolite could be a disadvantage because there is no reuse possibility. The authors highlighted that the method was simple, fast and a high preconcentration factor (i.e., 400) was obtained. On the other hand, Ghazaghi et al. $^{34}$ described a hybrid nanoadsorbent prepared by depositing graphene over the natural clinoptilolite $(G-C L)$ by chemical vapor deposition to preconcentrate $\mathrm{Pb}^{2+}$ and $\mathrm{Cd}^{2+}$ from water and human serum by ultrasound 
assisted $\mathrm{D}-\mu$-SPE. The nanoadsorbent was characterized by field emission scanning electron microscopy (FE-SEM) (Fig. 6), XRD, and energy dispersive X-ray (EDX) microanalysis, all of which revealed the high surface area of the graphene sheets on the natural clinoptilolite.

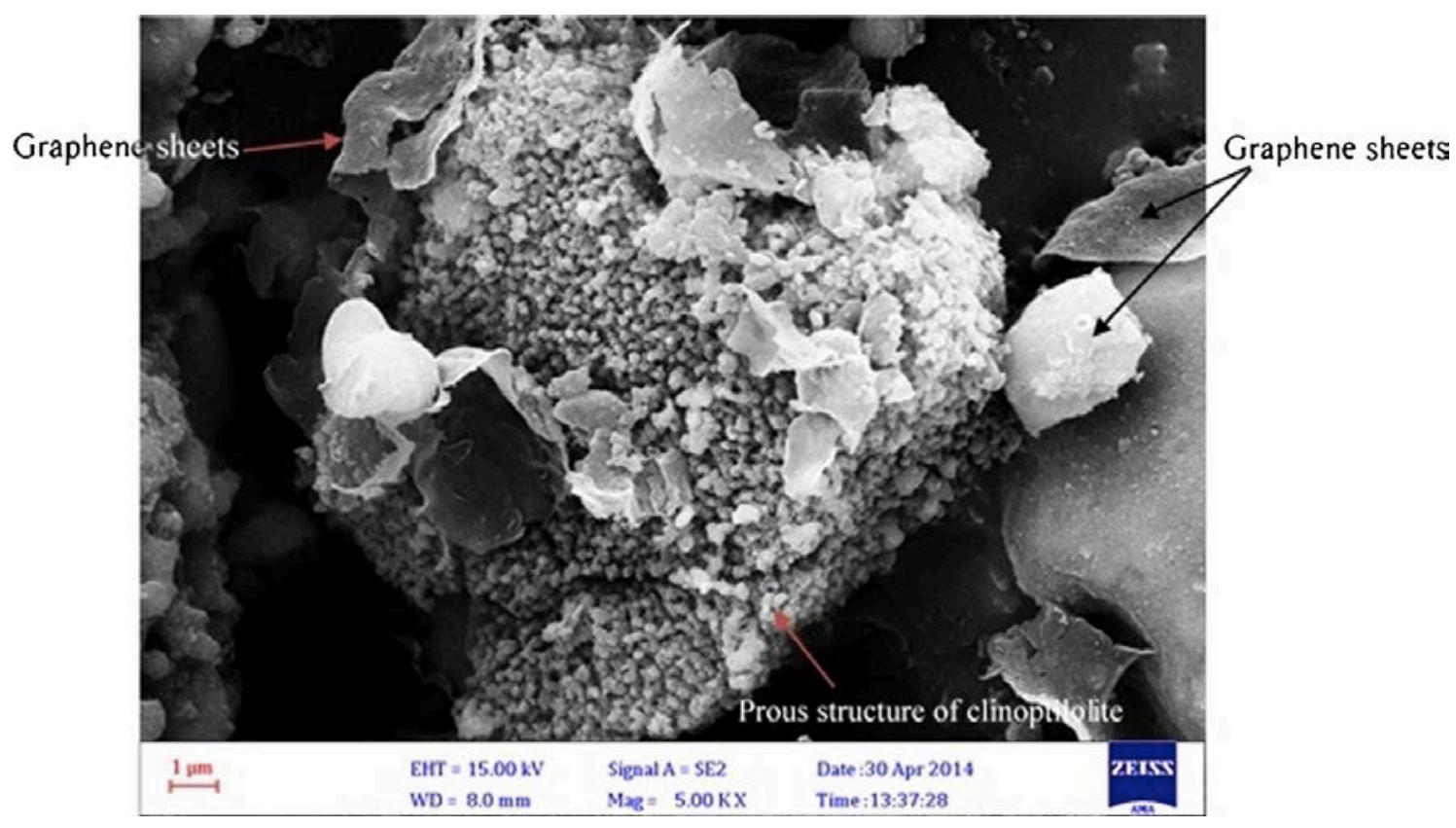

Fig. 6. FE-SEM image of G-CL hybrid. "Reprinted from Ref. ${ }^{23}$ with permission. Copyright (2015) Springer".

Comparison between G-CL hybrid and natural clinoptilolite as sorbents showed that efficiency of natural clinoptilolite both in water and serum samples was lower than that obtained with the G-CL hybrid, highlighting the low recoveries obtained for serum with natural clinoptilolite (i.e., lower than 9\%) versus recoveries higher than $97 \%$ using G-CL hybrid. This could be related with the fact that metal ions are bonded to proteins and large biomolecules, therefore graphene sheets were a barrier against the macromolecules, so metal ions can penetrated through the porous structure of clinoptilolite, while part of the metal ions that bonds with the proteins of plasma, can be adsorbed on the 
surface of the graphene, so whole the metal ions (free and bonded) can be extracted. The main advantages of this method were that both sample volume (i.e., $2 \mathrm{~mL}$ ) and sorbent amount (i.e., $5 \mathrm{mg}$ ) were very low, and therefore, suitable for biological approaches. Additionally, metal ions could be adsorbed without any chelating agent.

\subsection{Magnetic solid-phase extraction}

To our knowledge, only two publications have reported up to now about the use of zeolites decorated with magnetic nanoparticles as sorbent for preconcentration of heavy metals. In the first publication, 2-(3,4dihydroxyphenyl)-1,3-dithiane (DHPDT) modified magnetic NaY zeolite was presented as a new sorbent for MSPE. In this work, Shirani et al. ${ }^{19}$ determined $\mathrm{Cd}^{2+}$ and $\mathrm{Cu}^{2+}$ in water and soil samples by FAAS. Firstly, magnetic NaY zeolite was synthesized mixing $\mathrm{NaY}$ zeolite in $\mathrm{NH}_{4} \mathrm{OH}$ solution with $\mathrm{FeCl}_{3} \cdot 6 \mathrm{H}_{2} \mathrm{O}$ and $\mathrm{FeSO}_{4} \cdot 4 \mathrm{H}_{2} \mathrm{O}$ in $\mathrm{HCl}$ solution under a nitrogen atmosphere by ultrasonic treatment. Then, DHPDT modified magnetic NaY zeolite was prepared by magnetic stirring NaY zeolite with DHPDT in a methanol solution. The magnetic curve in Fig. 7 shows the appropriate superparamagnetic property of the magnetic modified NaY zeolite as seen by the lack of a hysteresis loop and no remanence existence. It should be noted that in the extraction procedure the sorbent was separated and the upper aqueous phase (i.e., supernatant) containing the residual $\mathrm{Cd}^{2+}$ and $\mathrm{Cu}^{2+}$ in the solution was used for determination by FI-FAAS. A three-layer artificial neural network model was developed to predict the simultaneous removal of $\mathrm{Cd}^{2+}$ and $\mathrm{Cu}^{2+}$. The results indicated that 
the proposed artificial neural network model could perfectly predict the process showing a close correlation between the experimental and predicted values.

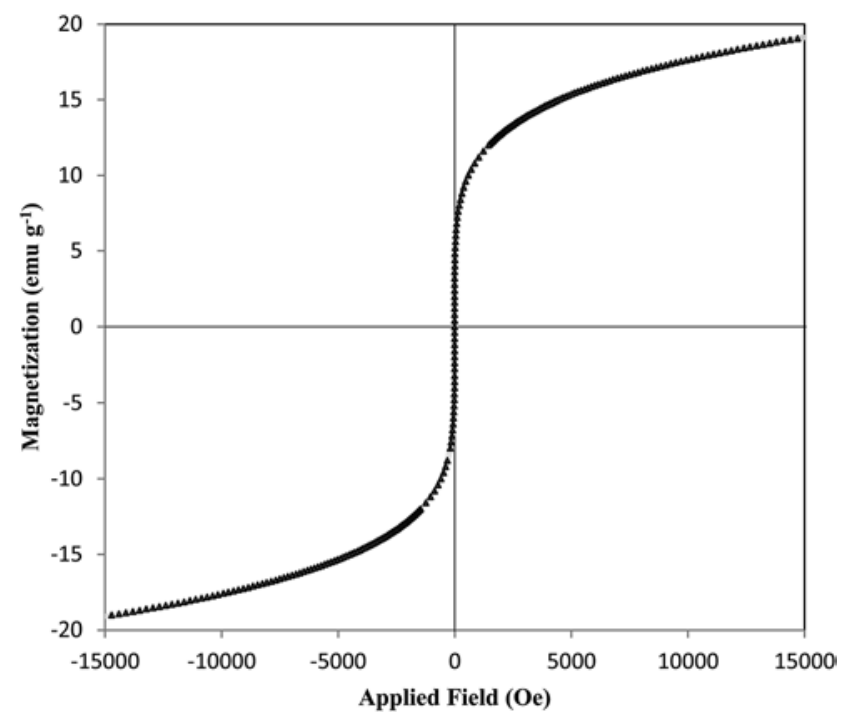

Fig. 7. The hysteresis loop of the magnetic organo-modified zeolite. "Reproduced from Ref. ${ }^{16}$ with permission of The Royal Society of Chemistry. Copyright (2015)".

The sorbent was reused up to 3 times showing constant adsorption efficiency, but it needed a previous regeneration. Finally, the comparison of the evaluation parameters of the proposed method with other methods such as adsorption time, sorbent mass and sorption capacity showed better results. Considering these results, authors concluded that the novel DHPDT modified magnetic NaY zeolite could be properly applied in an industrial scale. Finally, it should be mentioned a recent report published by our research group to determine $\mathrm{Cd}^{2+}, \mathrm{Hg}^{2+}$ and $\mathrm{Pb}^{2+}$ in urine samples by inductively coupled plasma optical emission spectrometry (ICP OES). ${ }^{20}$ This work employed a composite based on ZSM-5 zeolite decorated with magnetic iron oxide nanoparticles (i.e., $\mathrm{ZSM}-5 / \mathrm{Fe}_{2} \mathrm{O}_{3}$ ). This composite was first impregnated with $\mathrm{Zn}$ and then modified 
with HDTMA-Br and sodium diethyldithiocarbamate trihydrate (DDTC) (i.e., DDTC-HDTMA-Zn-ZSM-5/Fe $\mathrm{O}_{3}$ ). Comparison between ZSM-5/Fe $\mathrm{O}_{3}$, ZnZSM-5/Fe ${ }_{2} \mathrm{O}_{3}$ and DDTC-HDTMA-Zn-ZSM-5/Fe $\mathrm{O}_{2} \mathrm{O}_{3}$ showed that efficiency of DDTC-HDTMA-Zn-ZSM-5/Fe ${ }_{2} \mathrm{O}_{3}$ in urine samples was higher than the obtained with the other sorbents. A possible explanation was that urine contains certain compounds (i.e., proteins and large biomolecules) that act as chelating agents and could, therefore, form complexes with the studied analytes (i.e., Hg). A twostep multivariate strategy, using Plackett-Burman and circumscribed central composite designs, was employed to optimize experimental parameters affecting MSPE. Finally, good extraction efficiencies were obtained for $\mathrm{Hg}^{2+}$ and $\mathrm{Pb}^{2+}$ and the low value obtained for $\mathrm{Cd}^{2+}$ could be explained through the compromised extraction conditions chosen. However, the LOD values satisfy the threshold limit established by the Ministry of Labour and Social Affairs (Spain) for normal content of these metals in human urine and by the World Health Organization for normal mercury content in urine..$^{85,86}$ 


\section{Conclusions}

Natural and synthetic raw zeolites have been successfully employed for the extraction of organic compounds and metals. However, most of the studies done up to date employ zeolites modified with different reagents such as surfactants, chelating agents and metallic particles, among others. These modifications offer a wide range of extraction possibilities because the desired properties can be easily tuned. Another important aspect to point out is the versatility of the zeolites to distinct conformations upon request, mainly as a thin-film, packed in a cartridge, disperse in solutions and as a SPME fiber. Additionally, the whole procedure (i.e., synthesis, modification, extraction system assembly, etc.) can be lab made, what goes in the direction to open source philosophy. Despite these advantages, zeolites also possess some limitations. For instance, the widespread use of modified zeolites evidences the boundary of raw zeolites, especially for organic compounds extraction. Furthermore, most of the studies are devoted to the determination of a single analyte, being less environmental friendly methodologies; and only four studies have developed automated procedures, ${ }^{13,40,50,51}$ what could be fixed as a goal in the near future.

On the other hand, zeolites have strong competitors in the extraction field such as other ordered mesoporous materials, molecularly imprinted polymers or metal-organic frameworks. However, zeolites present some advantages over other materials. For example, their natural origin or economical synthesis procedure (in case of synthetic zeolites) provides zeolites in large amounts being considered low cost sorbents. The high chemical and water stability makes zeolites robust materials, being able to work not only under mild 
conditions but also in heavy environments. Based on this statement, zeolite and zeolite-based materials can be reused for numerous extractions without significant alterations in their performance, doing the procedure more environmentally friendly.

To conclude, Granda Valdés et al. $^{3}$ already highlighted the great analytical potential of these materials, but their potential is still waiting to be exploited 12 years later. Additionally, every year new zeolites are being discovered or synthesized, thus opening the gate towards the exploration and discovery of new challenges.

\section{Conflicts of interest}

There are no conflicts to declare

\section{Acknowledgements}

The authors would like to thank the Spanish Ministry of Economy and Competitiveness and European Union (FEDER funds) (project n. CTQ201679991-R) for the financial support. P. Baile also thanks Ministry of Education, Culture and Sports for her FPU grant (FPU14/04589). The authors also would like to thank Prof. Joaquín Silvestre-Albero for his fruitful discussion. 


\section{References}

1 B. Trewyn, Heterogeneous catalysis for today's challenges: synthesis, characterization and applications, Royal Society of Chemistry Publishing, Cambridge, 2015.

2 S. M. Auerbach, K. A. Carrado and P. K. Dutta, Handbook of zeolite science and technology, Marcel Dekker, New York, 2003.

3 M. G. Valdés, A. I. Pérez-Cordoves and M. E. Díaz-García, TrAC Trends Anal. Chem., 2006, 25, 24-30.

4 S. Wang and Y. Peng, Chem. Eng. J., 2010, 16, 11-24.

5 Structure Commission of the International Zeolite Association, http://www.iza-structure.org/, (July 2018).

6 C. Martínez and J. Pérez-Pariente, Zeolites and ordered porous solids: fundamentals and applications, Universitat Politècnica de València, Valencia, 2011.

7 O. Marincas, P. Petrov, T. Ternes, V. Avram and Z. Moldovan, J. Phys. Conf. Ser., 2009, 182, 012040.

8 E. Fernández and L. Vidal, in Miniaturization in Sample Preparation, ed. F. Pena-Pereira, De Gruyter OPEN, Warsaw, 2014, pp. 191-237.

9 C. F. Poole, TrAC Trends Anal. Chem., 2003, 22, 362-373.

10 C. L. Arthur and J. Pawliszyn, Anal. Chem., 1990, 62, 2145-2148.

11 V. O. Vasylechko, L. O. Lebedynets, G. V. Gryshchouk, R. Leboda and J. Skubiszewka-Zieba, Chem. Anal., 1999, 44, 1013-1024.

12 P. Arnnok and R. Burakham, J. Braz. Chem. Soc., 2014, 25, 1720-1729.

13 P. Arnnok, N. Patdhanagul and R. Burakham, Chromatographia, 2015, 78, 1327-1337. 
14 T. Shamspur, I. Sheikhshoaie and M. H. Mashhadizadeh, J. Anal. At. Spectrom., 2005, 20, 476-478.

D. Afzali, A. Mostafavi, M. A. Taher, E. Rezaeipour and M. Khayatzadeh Mahani, Anal. Sci., 2005, 21, 383-386.

16 A. Mollahosseini, M. Toghroli and M. Kamankesh, J. Sep. Sci., 2015, 38, 3750-3757.

17 S. Zhou, Z. Li, X. Lv, B. Hu and Q. Jia, Analyst, 2015, 140, 5944-5952.

18 E. Fernández, L. Vidal and A. Canals, J. Chromatogr. A, 2016, 1458, 1824.

19 M. Shirani, A. Akbari and M. Hassani, Anal. Methods, 2015, 7, 60126020.

20 P. Baile, L. Vidal, M. Á. Aguirre and A. Canals, J. Anal. At. Spectrom., 2018, 33, 856-866.

21 Y. S. Al-Degs, A. H. El-Sheikh, M. A. Al-Ghouti, B. Hemmateenejad and G. M. Walker, Talanta, 2008, 75, 904-915.

22 Y. S. Al-Degs and J. A. Sweileh, Arab. J. Chem., 2012, 5, 219-224.

23 D. Bergé-Lefranc, H. Pizzala, R. Denoyel, V. Hornebecq, J. L. BergéLefranc, R. Guieu, P. Brunet, H. Ghobarkar and O. Schäf, Micropor. Mesopor. Mater., 2009, 119, 186-192.

24 T. Pasinli and E. Henden, Ekoloji, 2013, 22, 57-66.

25 X. Chen, S. Chen, J. Liu and J. Wang, Microchim. Acta, 2009, 165, 217222.

26 V. O. Vasylechko, G. V. Gryshchouk, V. P. Zakordonskiy, O. Vyviurska and A. V. Pashuk, Chem. Cent. J., 2015, 9, 45-51. 
27 S. Hajialigol, M. A. Taher and A. Malekpour, J. AOAC Int., 2008, 91, 1446-1452.

28 A. Malekpour, S. Hajialigol and M. A. Taher, J. Hazard. Mater., 2009, 172 , 229-233.

29 L. Rostampour and M. A. Taher, Talanta, 2008, 75, 1279-1283.

30 R. Roohparvar, M. A. Taher and A. Mohadesi, J. AOAC Int., 2008, 91, 637-645.

31 A. Mohadesi, R. Roohparvar and M. A. Taher, Trans. Univ. Kosice, 2008, 3, 112-119.

32 S. Z. Mohammadi, R. Roohparvar and M. A. Taher, J. Anal. Chem., 2016, 71, $42-49$.

33 H. Faghihian and M. Kabiri-Tadi, Microchim. Acta, 2010, 168, 147-152.

34 M. Ghazaghi, H. Shirkhanloo, H. Z. Mousavi and A. M. Rashidi, Microchim. Acta, 2015, 182, 1263-1272.

35 M. C. Dumlao, L. E. Jeffress, J. J. Gooding and W. A. Donald, Analyst, 2016, 141, 3714-3721.

36 S. Goda, R. Selyanchyn, T. Nozoe, H. Matsui and S. W. Lee, J. Anal. Bioanal. Tech., 2014, 004/1-004/7.

37 T. P. Lee, B. Saad, E. P. Ng and B. Salleh, J. Chromatogr. A, 2012, 1237, 46-54.

38 C. L. Rodgers, K. A. St. Pierre and A. B. Hall, Forensic Sci. Int., 2014, 240, 144-150.

39 K. A. St. Pierre, V. J. Desiderio and A. B. Hall, Forensic Sci. Int., 2014, 240, 137-143. 
40 Y. Petit De Peña, W. López, J. L. Burguera, M. Burguera, M. Gallignani, R. Brunetto, P. Carrero, C. Rondon and F. Imbert, Anal. Chim. Acta, 2000, 403, 249-258.

41 M. A. Taher, A. Mostafavi and S. Z. Mohammadi, Asian J. Chem., 2005, $17,1456-1462$.

42 D. Afzali, A. Mostafavi, M. A. Taher and A. Moradian, Talanta, 2007, 71, 971-975.

43 A. S. Saljooghi, S. J. Fatemi and D. Afzali, Bull. Chem. Soc. Ethiop., 2010, 24, 127-132.

44 A. S. Saljooghi and Z. S. Saljoghi, Toxicol. Ind. Health, 2012, 28, 771778.

45 M. A. Taher, A. Mostafavi and S. Z. Mohammadi, J. Anal. Chem., 2007, 62, 1022-1027.

46 R. Jamshidi, Z. Afzali and K. Afzali, Asian J. Chem., 2009, 21, 3381-3384.

47 P. Arnnok, N. Patdhanagul and R. Burakham, Talanta, 2017, 164, 651661.

48 P. Salisaeng, P. Arnnok, N. Patdhanagul and R. Burakham, J. Agric. Food Chem., 2016, 64, 2145-2152.

49 S. A. Rezvani and A. Soleymanpour, J. Chromatogr. A, 2016, 1436, 3441.

50 Y. Petit De Peña, B. Paredes, W. Rondón, M. Burguera, J. L. Burguera, C. Rondón, P. Carrero and T. Capote, Talanta, 2004, 64, 1351-1358.

51 Y. Petit De Peña and W. Rondón, Am. J. Anal. Chem., 2013, 4, 387-397.

52 A. Mostafavi, D. Afzali and M. A. Taher, Anal. Sci., 2006, 22, 849-853. 
53 H. Minamisawa, R. Okunugi, M. Minamisawa, S. Tanaka, K. Saitoh, N. Arai and M. Shibukawa, Anal. Sci., 2006, 22, 709-713.

54 Y. Tao, Y. Jiang, W. Li and B. Cai, RSC Adv., 2016, 6, 98476-98486.

55 W. B. Wilson, A. A. Costa, H. Wang, J. A. Dias, S. C. L. Dias and A. D. Campiglia, Anal. Chim. Acta, 2012, 733, 103-109.

56 W. B. Wilson, A. A. Costa, H. Wang, A. D. Campiglia, J. A. Dias and S. C. L. Dias, Microchem. J., 2013, 110, 246-255.

57 H. Yapati, S. Bhogineni, S. Chirumamilla and K. Seshaiah, J. Chem. Sci., 2016, 128, 779-786.

58 F. Augusto, L. W. Hantao, N. G. S. Mogollón and S. C. G. N. Braga, TrAC Trends Anal. Chem., 2013, 43, 14-23.

59 A. Mehdinia and M. O. Aziz-Zanjani, TrAC Trends Anal. Chem., 2013, 51, 13-22.

60 J. Xu, J. Zheng, J. Tian, F. Zhu, F. Zeng, C. Su and G. Ouyang, TrAC Trends Anal. Chem., 2013, 47, 68-83.

61 N. Gilart, F. Borrull, N. Fontanals and R. M. Marcé, Trends Environ. Anal. Chem., 2014, 1, e8-e18.

62 B. H. Fumes, M. R. Silva, F. N. Andrade, C. E. D. Nazario and F. M. Lanças, TrAC Trends Anal. Chem., 2015, 71, 9-25.

63 A. A. Matin, R. Maleki, M. A. Farajzadeh, K. Farhadi, R. Hosseinzadeh and A. Jouyban, Chromatographia, 2007, 66, 383-387.

64 A. Chalabiani, A. A. Matin and K. Farhadi, J. Chinese Chem. Soc., 2012, 59, 1080-1085.

65 H. Wang, Z. Li, Q. Niu, J. Ma and Q. Jia, Appl. Surf. Sci., 2015, 353, 1326-1333. 
D. Bergé-Lefranc, O. Schäf, R. Denoyel, J. L. Bergé-Lefranc, R. Guieu, P. Brunet and V. Hornebecq, Micropor. Mesopor. Mater., 2010, 129, 144148.

67 Z. Du, J. Mo, Y. Zhang, X. Li and Q. Xu, Anal. Methods, 2013, 5, 34633472.

68 M. Ghazi-Khansari, R. Zendehdel, M. Pirali-Hamedani and M. Amini, Clin. Chim. Acta, 2006, 364, 235-238.

69 M. Cruz-Vera, R. Lucena, S. Cárdenas and M. Valcárcel, Anal. Methods, 2011, 3, 1719-1728.

70 S. Risticevic, V. H. Niri, D. Vuckovic and J. Pawliszyn, Anal. Bioanal. Chem., 2009, 393, 781-795.

71 J. Płotka-Wasylka, N. Szczepańska, M. de la Guardia and J. Namieśnik, TrAC Trends Anal. Chem., 2015, 73, 19-38.

72 A. A. Costa, W. B. Wilson, H. Wang, A. D. Campiglia, J. A. Dias and S. C. L. Dias, Micropor. Mesopor. Mater., 2012, 149, 186-192.

73 M. He, L. Huang, B. Zhao, B. Chen and B. Hu, Anal. Chim. Acta, 2017, 973, 1-24.

74 Ş. Tokalıoğlu, E. Yavuz, S. Demir and Ş. Patat, Food Chem., 2017, 237, 707-715.

75 F. Shakerian, K. H. Kim, E. Kwon, J. E. Szulejko, P. Kumar, S. Dadfarnia and A. M. Haji Shabani, TrAC Trends Anal. Chem., 2016, 83, 55-69.

76 J. Sun, Q. Liang, Q. Han, X. Zhang and M. Ding, Talanta, 2015, 132, 557563. 
77 A. I. Corps Ricardo, A. Sánchez-Cachero, M. Jiménez-Moreno, F. J. Guzmán Bernardo, R. C. Rodríguez Martín-Doimeadios and Á. Ríos, Talanta, 2018, 179, 442-447.

78 S. Saraçǒlu and L. Elçi, Anal. Chim. Acta, 2002, 452, 77-83.

79 V. Gurnani, A. K. Singh and B. Venkataramani, Anal. Chim. Acta, 2003, 485, 221-232.

80 N. Pourreza and H. Z. Mousavi, Talanta, 2004, 64, 264-267.

81 B. Armağan, M. Turan and M. S. Çelik, Desalination, 2004, 170, 33-39.

82 M. Anari-Anaraki and A. Nezamzadeh-Ejhieh, J. Colloid Interface Sci., 2015, 440, 272-281.

83 S. Boudra, J. M. Bosque-Sendra and M. C. Valencia, Talanta, 1995, 42, $1525-1532$

84 J. Wang, D. Lu, S. Thongngamdee, Y. Lin and O. A. Sadik, Talanta, 2006, 69, 914-917.

85 World Health Organization, Guidelines for drinking-water quality, Geneva, 2008

86 INSHT, NTP 109: Biological threshold values for metals exposures monitoring, Ministry of Labour and Social Affairs (Spain), 1984. 